\title{
Electrospun nanowire arrays for electronics and optoelectronics
}

\author{
Zhi Zheng, Lin Gan and Tianyou Zhai*
}

\begin{abstract}
Alignment of NWs (NWs) is the core issue for integrating NWs into nanodevices in future. This review made a concise retrospect on reported assembling methods and mainly emphasized on the electrospinning method and its developments, as well as the following applications of the aligned nanowire array (NWA) in electronics and optoelectronics. First, we classified reported assembling methods into three categories: "grow then place", "place then grow" and "grow and place" (electrospinning method). Then, we focused on the electrospinning method and its modified method including field assisted method, rotating collector assisted method and near-field assisted methods, as well as their merits and defects, respectively. Next, we illustrated the applications of the NWs arrays fabricated by electrospinning in field effect transistors (FET), gas sensors, piezoelectric sensors and photodetectors. Finally, we made a short conclusion and prospection on electrospinning method. As an easy and cheap nanowire fabrication and alignment method, electrospinning has a bright future in one-dimensional materials based electronics and optoelectronics.
\end{abstract}

Keywords: electrospinning, aligned nanowire array, electronics, optoelectronics

\section{INTRODUCTION}

One-dimensional (1D) semiconductor nanowires (NWs) are ideal building blocks for nano-circuit not only because of their unique electrical and optical properties [1-3], but also for their compatibility to be both conducting channel and connecting wires in the circuit. With the rapid development of electronics and optoelectronics, the requirements on the miniaturization and functionalization of devices motivate fast growing researches in regarding to nanostructures fabrication and alignment [4]. Furthermore, the improving integration density of nano-circuit requests a highly ordered arrangement for targeting nanostructures. Therefore, the alignment methods used to fabricate nanostructures are significant.
Electrospinning is a cheap and stable technique that allows the fabrication of continuous and uniform fibers, either organic or inorganic, with diameters ranging from tens of nanometers to several micrometers for mass production [5-7]. Moreover, highly ordered aligned nanowire array (NWA) can also be easily achieved on various substrates based on modified electrospinning, which is greatly beneficial to the following applications of NWs in various fields shown in Fig. 1. In this review, we provide a concise retrospection on the assembling methods and primarily highlight the electrospinning method and corresponding applications of NWA including electrodes, field effect transistors (FET), piezoelectric sensor, gas sensor, and photodetectors. We also give comments and prospection in the

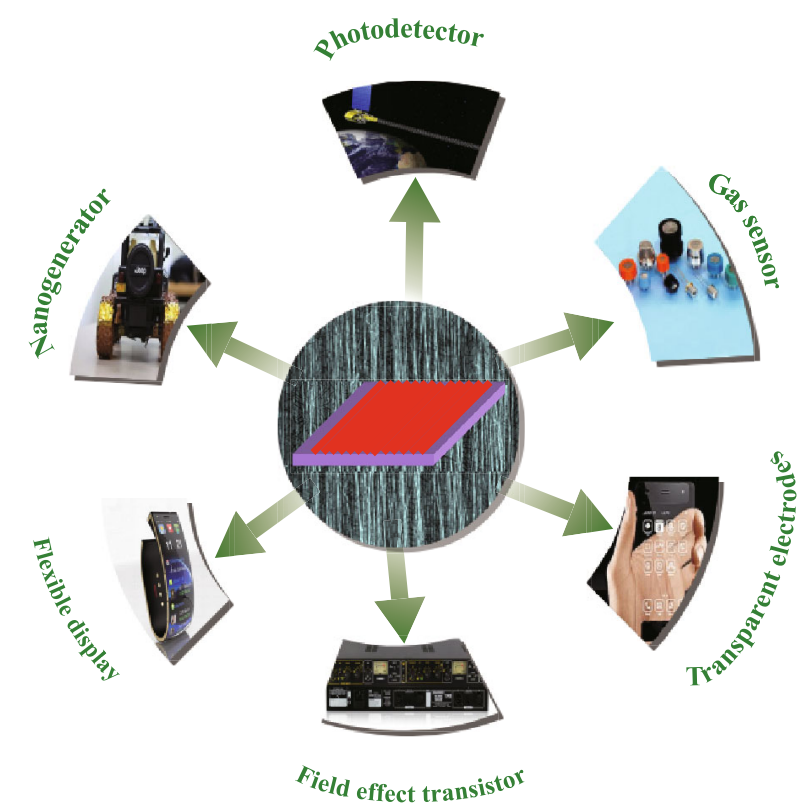

Figure 1 Applications of NWA in transparent electrodes, FET, gas sensor, photodetector and flexible displays.

State Key Laboratory of Material Processing and Die \& Mould Technology, School of Materials Science and Engineering, Huazhong University of Science and Technology (HUST), Wuhan 430074, China

"Corresponding author (email: zhaity@hust.edu.cn) 
final section on the future development of electrospinning method.

\section{METHODS TO ASSEMBLE NWs}

Generally there are two modes of NWs assembly, that is, vertical and horizontal assemblies. However, for the vertical NWs assembly methods, many excellent review papers have made comprehensively summaries on it [8-10], thus in this review, we exclusively concentrate on horizontal assembly methods. Moreover, there is almost no restriction on the choice of substrates and depositing layer numbers and angles of NWs for horizontal assembly [11,12], which also make such an array mode important. In this review, we further classify all horizontal assembling into three kinds: "grow then place", "place then grow" and "grow and place", namely, electrospinning method as shown in Fig. 2.

\section{"Grow then place" method}

As-synthesized NWs usually are randomly distributed [13-17]. To align those messy NWs, many strategies have been proposed, for instance, electric/magnetic-field, contact/roll printing techniques, electrostatic interaction, Langmuir-Blodgett (LB), bubble-blown techniques, as shown in Fig. 3. In this section, we briefly introduce several important approaches [18].

As vividly reported by Yang et al. [19], LB is a technique that transfer nanomaterials onto a targeting substrate as a form of monolayer (LB film) with a high degree of structure order as shown in Fig. 3a [20]. This technique has been also extended to other 1D NWs such as Ag NWs [21], Ge NWs [22], $\mathrm{V}_{2} \mathrm{O}_{5}$ NWs [23], ZnSe NWs [24], PbS NWs and $\mathrm{BaCrO}_{4}$ nanorods $[25,26]$. However, surfactants are necessary for this technique to modify the surface of NWs and prevent the aggregation of NWs. Blown bubble method is another method to prepare density controlled and wellaligned NW pattern [27]. Generally, the aligned nanoma- terials exist as a free standing films that can be transferred onto various substrates such as rigid, flexible and curved substrates (Fig. 3b) [11]. But the necessary shapable matrix is difficult to remove after alignment. Direct interactions between the NWs and the patterned surfaces can also be utilized to selectively align NWs [28,29]. Usually, the NWs exhibit strong affinity to polar self-assembled monolayer patterns, for example, single wall carbon nanotubes (SWCNTs) show strong affinity to most bare surfaces ( $\mathrm{Au}$, $\mathrm{Si}, \mathrm{Al}, \mathrm{SiO}_{2}$, and glass) (Fig. 3c) [30]. The drawback of this technique is that the alignment quality of NWs is low. Contact printing is a method that can operate in a non-liquid environment [31-34]. Briefly speaking, this technique can transfer NWs from growth substrate to receiver substrate with the help of directional shear force as shown in Fig. $3 d$ [33]. During this process, the ends of NWs stick to the receiver substrate by the van der Waals interactions, and the remaining length is aligned by the pulling force. This method is fit to various materials, including $\mathrm{Zn}_{3} \mathrm{As}_{2}$ [35], X(In, Ga)P [36], Ge [37], Si [38], SWCNTs [39]. However, requirements that materials should typically grow vertically on the substrate may limit its application. Field assisted methods align NWs normally using the dielectrophoresis (DEP) or magnetic field $[40,41]$. This alignment mechanism can be clearly illustrated in Fig. 3e. The existed charge neutral regions in the pn Si NWs will be polarized when exposed to a direct current electric field. Then the DEP forces will attract the pn Si NWs to the electrode edges, on the other side, NWs will be adjusted to parallel to each other. The drawback of this method is that prefabricated microelectrode arrays are needed and reorientation and aggregation of the NWs will occur if solvent is evaporated [42].

\section{"Place then grow" method}

The "grow then place" method can align NWs and control

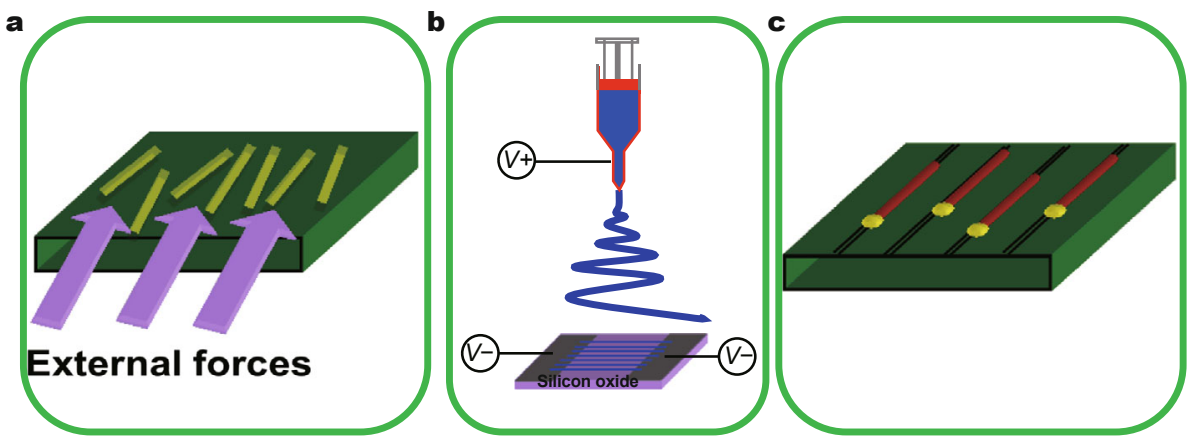

Figure 2 Schematic illustration of methods for assembling NWs. (a) "Grow then place" method. (b) "Grow and place", namely, electrospinning method. (c) "Place then grow" method. 
a
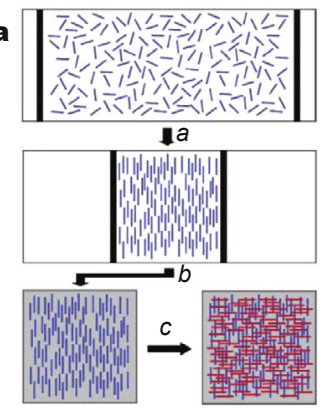

b

(i)

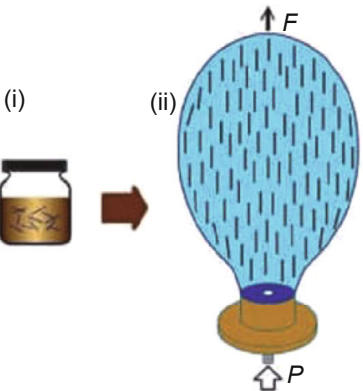

(iii)

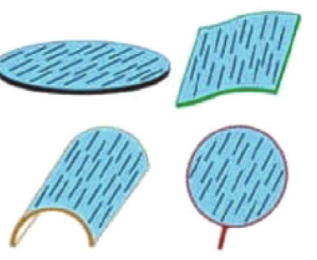

c

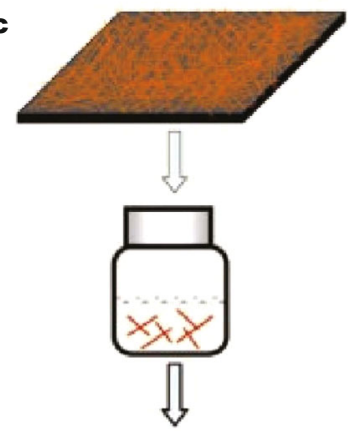

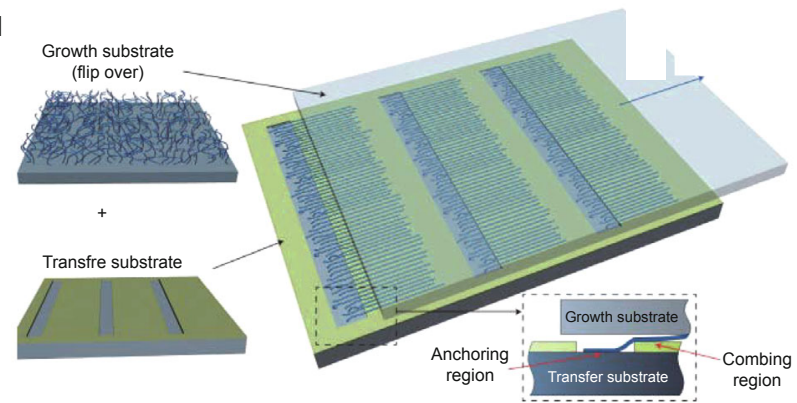

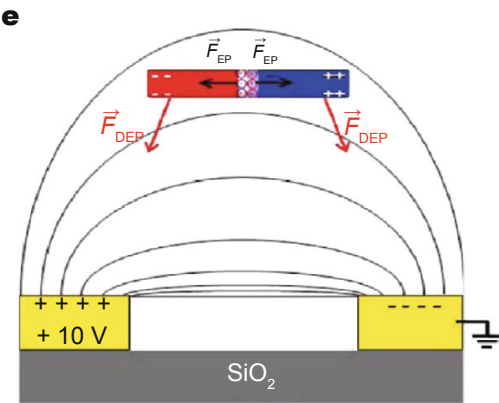

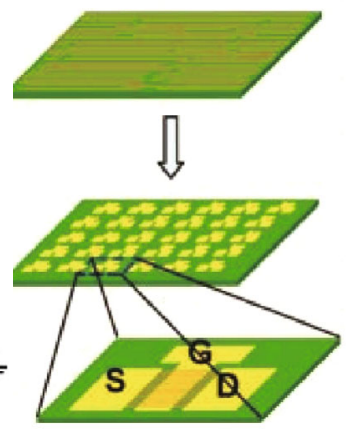

Figure 3 Typical methods of "grow then place" strategy. (a) Assembling by LB method. Reprinted with permission from Ref. [20] (Copyright 2003, American Chemical Society). (b) Assembling by blown bubble method. Reprinted with permission from Ref. [11] (Copyright 2007, Nature Publishing Group). (c) Assembling by molecular inter-atomic forces. Reprinted with permission from Ref. [30] (Copyright 2003, Nature Publishing Group). (d) Assembling NWs by mechanical shear forces. Reprinted with permission from Ref. [33] (Copyright 2013, Nature Publishing Group). (e) Assembling NWs by electric field force. Reprinted with permission from Ref. [42] (Copyright 2010, American Chemical Society).

the locations in some degree. However, the "place" processing is carried out in a transfer media and NWs should be modified with functional group which may influence the surface cleanness of the NWs and the device performance.

Recently, a "place then grow" strategy was investigated by researchers. This technique refers to grow aligned NWs on specific locations and take a predetermined orientation with one step. A creative way is utilizing the growth of laterally oriented Si NWs between vertical (111) Si planes via etching a (110)-oriented Si wafer as shown in Fig. 4a [43]. This is a facile way to construct electronic devices in nano scale. However, NW species, density and numbers are not easy to control. An easier way as shown in Fig. 4b is to sputter the Au pad using a metal mask on a quartz substrate. Li et al. [44] grow the $\mathrm{ZnO}$ bascule nanobridges which have high sensitivity and fast response to the UV light. Controllable planar $<110>$ GaAs NW array on GaAs (100) substrates can be obtained at higher growth temperature $\left(>450^{\circ} \mathrm{C}\right)$ as shown in Fig. $4 \mathrm{c}$. Direction of growth between the NWs and planar can be adjusted by growth temperature [45]. Further, Tsivion et al. [46] can accurately control the growth morphology and crystallographic orientation via vapor-liquid-solid (VLS) growth mode. The growth mode which decides the growth morphology has a close relationship to the substrates' symmetry as follows: (a) growth along specific lattice directions, (b) graphoepitaxial growth along nanosteps, (c) graphoepitaxial growth along nanogrooves. This strategy is also fit to other inorganic NWs such as GaN (Fig. 4d). However, it is difficult to obtain the substrate with different orientations to guide the growth. A confinement-guided growth method was adopted by Pevzner et al. [47] to predesign the synthesized NWs both in the chemical and physical attributes and the geometry as illustrated in Fig. 4e. This technique can extend to various substrates such as silicon wafer, quartz and glass slides, and even plastic substrates [47]. Moreover, in-plane epitaxy method has important applications in fabricating the p-n junctions [48]. For example, Yu et al. [48] reported this strategy to grow p-Si NWs arrays on $\mathrm{n}-\mathrm{Si}(100)$ substrates by plasma enhanced chemical vapor deposition (PECVD) (Fig. 4f).

Above all, the "place then grow" approaches have a better effect on alignment of NWs because the arrays are predesigned before NWs growth, in contrast with the "grow then place" strategy. However, this alignment may be limited to specific materials and substrates, such as Si NWs on (111) substrate of silicon. So a direct and much more universal assembling strategy should be explored. 


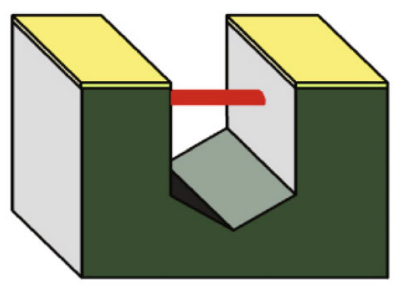

d

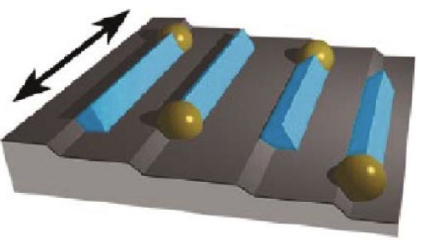

b

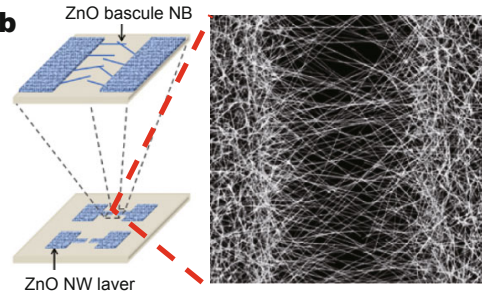

e

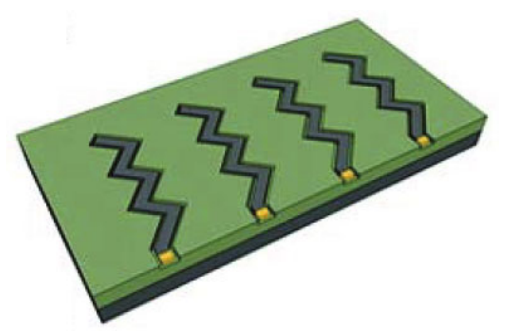

c

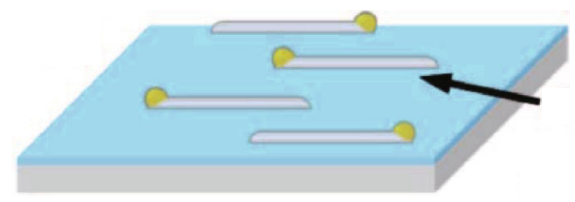

f

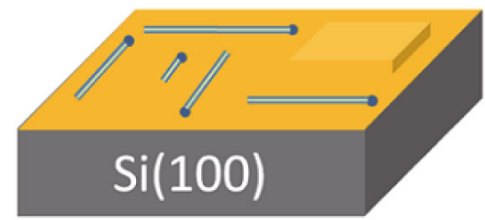

Figure 4 Schematic diagram of "place then grow" strategy. (a) Silicon nanobridges formed between two vertical silicon surfaces. Reprinted with permission from Ref. [43] (Copyright 2004, IOP Publishing Ltd.). (b) Bridge growth pattern of the ZnO bascule. Reprinted with permission from Ref. [39] (Copyright 2010, IOP Publishing Ltd). (c) GaAs NWs on GaAs (100) substrates. Reprinted with permission from Ref. [40] (Copyright 2008, American Chemical Society). (d) ZnO bascule nanobridges self-assembled in the gap. Reprinted with permission from Ref. [41] (Copyright 2012, American Chemical Society). (e) Confinement-guided shaping growth of silicon NWs. Reprinted with permission from Ref. [42] (Copyright 2012, American Chemical Society). (f) In-plane epitaxial growth of silicon NWs. Reprinted with permission from Ref. [43] (Copyright 2014, American Chemical Society).

\section{"Grow and place"-electrospinning method}

Electrospinning is a low cost and versatile strategy for fabricating NWs including organic and inorganic NWs [49]. Stable and rapid production process makes it one promising technique that meets the requirements of mass production. The principle of electrospinning is similar to the electrospray process [50]. The precursor liquid forms a Taylor cone during the electrospinning process at first and then turns into a charged jet under high electrostatic voltage. The charged jet will be further elongated and thinned separately under electrostatic force and Coulomb repulsion during travelling from outlet of injector to collector. However, the random orientations of the NWs may limit the application in electronics and optoelectronics. To avoid the messy collection of NWs, some modifications on electrospinning have been proposed as shown in Fig. 5. In the following part, we will give an introduction to such modifications including field assisted method [51-53], rotating collector assisted method [54-56] and near-field assisted method, etc. With the development of these improved techniques, electrospinning becomes a method that can conduct NWs growth and alignment simultaneously.

\section{Field assisted method}

In contrast to an integrated collecting electrode applied in conventional electrospinning method, well aligned NWs can be obtained by using two separated conductive substrates as the collector.
The precursor NWs are highly positively charged under high voltage, and the substrate is negatively charged. The movement of the NWs is influenced by two types of electrostatic interactions, that is, electrostatic force between charged NWs and collectors and the Coulomb repulsion between NWs deposited on separated electrodes. As a result, NWs would deposit in parallel on the separated electrodes. For example, Li et al. [12] use two pieces of silicon electrodes as the collector to align polymer NWs such as polyvinyl pyrrolidone (PVP), poly-(ethylene oxide) (PEO), polystyrene (PS), and polyacrylonitrile (PAN), as well as inorganic NWA such as $\mathrm{SnO}_{2}$ and $\mathrm{TiO}_{2}$. Interestingly, hollow NWA can be obtained by using the electrospinning methods as shown in Figs 6a and b [57]. Aligned hollow $\mathrm{TiO}_{2}$ NWs can be obtained by calcinating the inside layer of mineral oil. Besides, one can also fabricate the PVP NWA by electrospinning first, then deposit inorganic metal oxide materials followed by a heating process to obtain hollow NWs as shown in Fig. 6c [58]. Notably, external magnetic field could also be used to achieve similar results $[59,60]$. For example, Yang et al. [60] use two parallel-positioned permanent magnets to replace the electrodes, so the magnetic field will arrange the NWs containing magnetic nanoparticles under magnetic field (Fig. 6d).

\section{Rotating collector assisted method}

This method is to replace the static collector in conventional electrospinning method with a rotating collector [61]. 


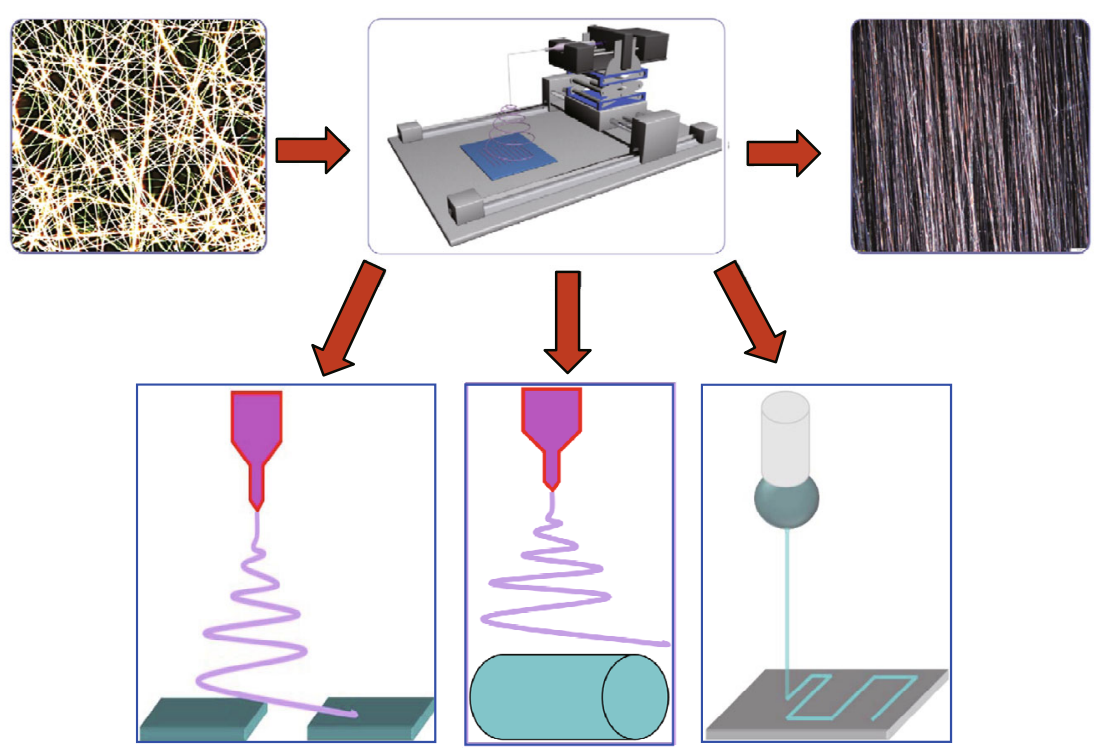

Figure 5 Schematic diagram for alignment via electrospinning, including field assisted method, rotating collector assisted method, and near-field method.

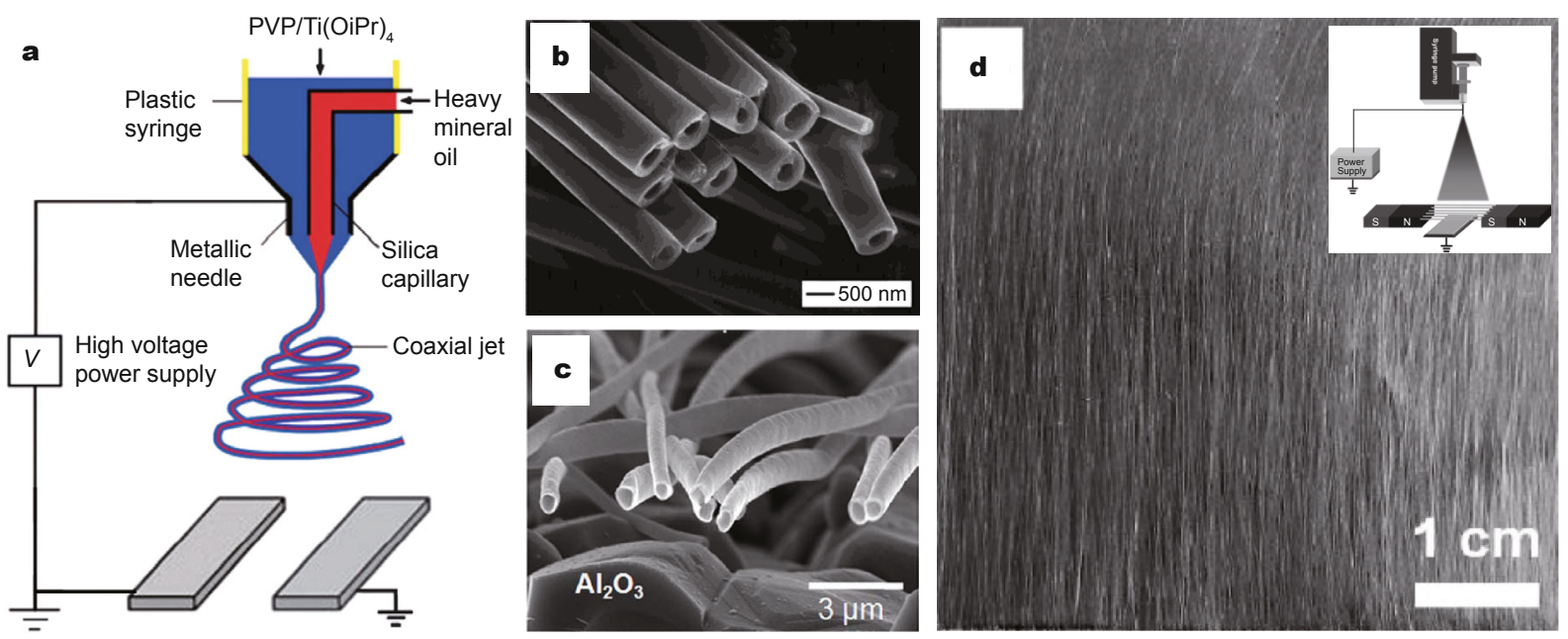

Figure 6 Assembling NWs by electrospinning with field assisted. (a) Schematic diagram for assembling hollow NWs via a pair of parallel separate electrodes. (b) Scanning electron microscopy (SEM) image of aligned hollow $\mathrm{TiO}_{2} \mathrm{NWs}$. Reprinted with permission from Ref. [57] (Copyright 2004, American Chemical Society). (c) SEM image of aligned hollow ZnO NWs. Reprinted with permission from Ref. [58] (Copyright 2009, American Chemical Society). (d) Assembling NWs via magnetic-field-assisted method. Reprinted with permission from Ref. [60] (Copyright 2010, WILEY-VCH Verlag GmbH \& Co. KGaA).

Generally the rotation speed of the collector has a significant influence on the alignment of the NWs [62]. Too high or too low speed will lead a disordered morphology. Recently, different shapes of collectors including a wire drum [54], a disc or a cone have been used to improve the alignment of the NWs $[63,64]$.

Katta et al. [54] used a copper wire-framed drum supported with two non-conducting disks as collectors to align NWs. Charged NWs will be stretched and span across the gap between the copper wires under electrostatic interactions. This strategy can align NWs in a large scale and the alignment quality is mainly affected by the rotation rate as shown in Fig. 7a. Another mode is to align NWs by using the sharp edge of a disc collector which offers the jet a pulling force along the tangent line of disc. Highly ordered and dense NWA of poly(L-lactide-co- $\varepsilon$-caprolactone) [P(LLA-CL $)]$ can be obtained on any substrates under an appropriate rotating speed (Figs $7 b$ and c) $[63,65]$. 

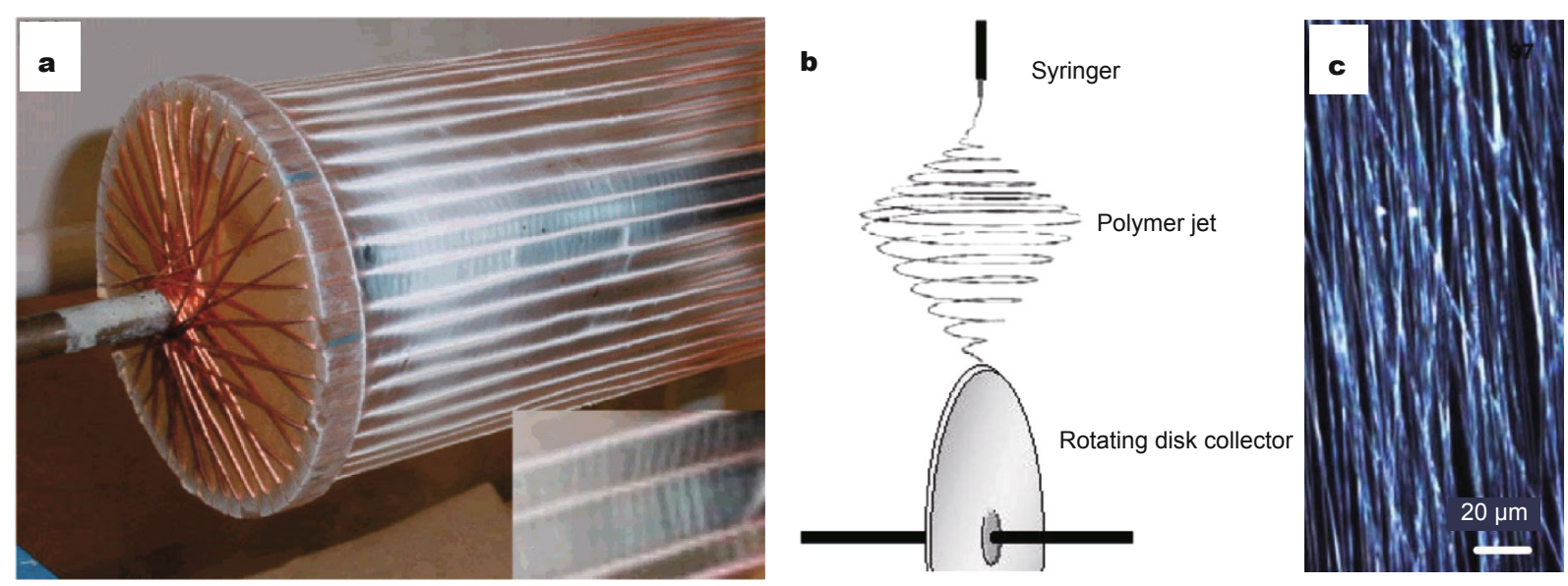

Figure 7 Assembling NWs by electrospinning with rotating collector. (a) Nylon NWs are aligned on copper wires. Reprinted with permission from Ref. [54] (Copyright 2004, American Chemical Society). (b) Assembling NWs with a disk collector. (c) Optical image of aligned P(LLA-CL) NWs. Reprinted with permission from Ref. [63] (Copyright 2004, Elsevier).

\section{Near-field electrospinning method and other modifications}

Besides the two strategies mentioned above, more improvements such as conductive template method [66,67], centrifugal electrospinning [68-70], and near-field electrospinning methods [71-74] have also been developed.

Conductive template method can be used to prepare NWs with complex ordered architectures and patterns [67]. Usually, the conductive templates are made of woven wires as shown in Fig. 8a. Coulomb interactions between positive and negative charges will lead the NWs to align along the wires. Moreover, both diameter of the metal wire and distance between two protrusions have influence on the parallelism and density of the array, respectively. Small diameters of NWs are inclined to form parallel array and density increases with decreasing distance between the protrusions. These specifically designed conductive template collectors have great potential for the fabrication of patterned fibrous mats which may be widely applied in biomedicine and its industry (Fig. 8b). A centrifugal or rotating jet method can also align NWs conveniently. The jet is cylindrical collector because of the opposite charges between the needle and the collector as shown in Fig. 8c. High density arrays even align 3D structure or any arbitrary shape by changing the geometry under a not very high voltage and easily operated process via this technique (Fig. 8d). Interestingly, Badrossamay et al. [68] combine centrifuge-spinning with traditional electrospinning which can fabricate superfine NWAs at low voltage $(2.8-3 \mathrm{kV})$ and slow rotating speed (390 rpm).

Most of the above strategies can obtain large area NWAs, but it is hard to adjust individual NWs. Near field electrospinning is a high-speed, individually controlled NWAs fabrication method (Figs 8e and f). The distance between electrodes and collectors is very short $(500 \mu \mathrm{m}-10 \mathrm{~mm})$ and the work voltage is low $(0.5-1.5 \mathrm{kV})$. It is a so called "direct write" technique because it can accurately deposit NWs on the substrate just like writing [73]. Such a highly controllable writing method benefits many applications like microelectronics and sensors [74].

\section{APPLICATIONS BASED ON NWA}

NWs fabricated by electrospinning methods can be directly deposited on the targeting substrate and therefore avoid the impurities or defects induced by transfer. Moreover, well aligned arrays can be utilized in electronics and optoelectronics based on 1D nanomaterials. In this part, we concentrate on the applications of NWA fabricated by electrospinning in electronics and optoelectronics.

\section{Electronic devices}

Compared with traditional disordered NW film devices, NWA has direct and fast carrier transport channel which improves the electronic properties of devices, furthermore, this regular and uniform structure is beneficial to integration of electronic circuits.

\section{Electrodes and FET}

NWA can be utilized as both electrodes and conducting channel in devices. Lin et al. [75] synthesized ZnO NWs composited with Ag nanoparticles to study the electrical behavior with different Ag content. The schematic of device is shown in Fig. 9a. Ag nanoparticles were doped by in situ photochemical reduction of silver nitrate mixed with zinc nitrate. $I-V$ curves demonstrate that current is 

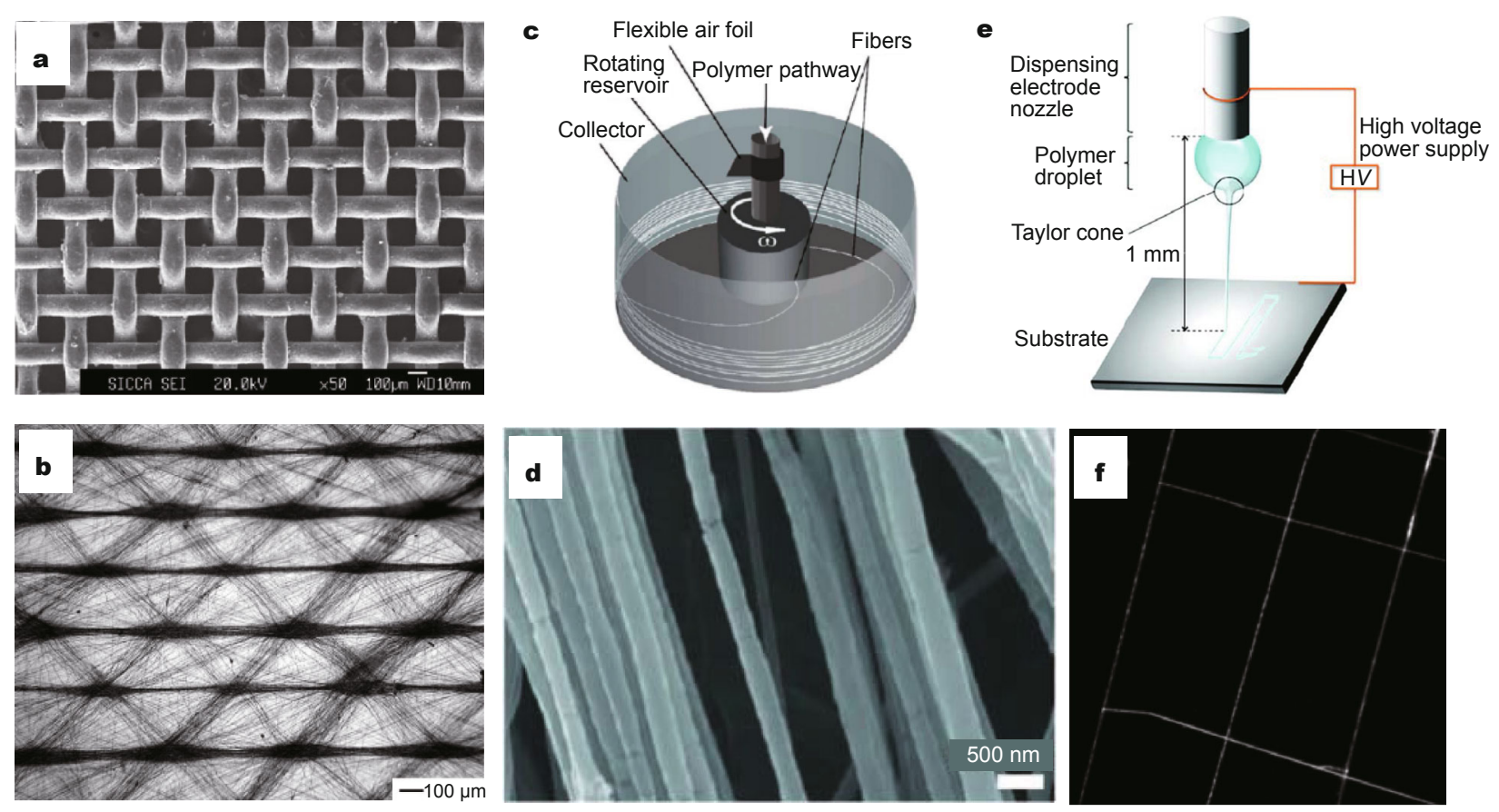

Figure 8 Assembling NWs by electrospinning with other approaches. (a) SEM image of a patterned collector. (b) Optical image of electrospun mat collected using the collector in (a). Reprinted with permission from Ref. [67] (Copyright 2007, WILEY-VCH Verlag GmbH \& Co. KGaA). (c) Schematic diagram of assembling NWs via rotary jet-spinning. (d) SEM image of the aligned polyethylene oxide (PEO) NWs. Reprinted with permission from Ref. [68] (Copyright 2010, American Chemical Society). (e) Schematic diagram of the printing process. (f) SEM images of printed PEO NWs. Reprinted with permission from Ref. [74] (Copyright 2011, American Chemical Society).

remarkably enhanced when $\mathrm{Ag}$ is added. The current is higher than that of pure $\mathrm{ZnO} \mathrm{NW}$ device by seven orders of magnitudes when the Ag content was $50 \%$, as shown in Fig. 9b. Detailed electronical intrinsic coefficient data as switch voltage $\left(V_{c}\right)$ and electrical nonlinear coefficient $\alpha$ are shown in Fig. $9 c . V_{c}$ decreases because Ag decreases the number of $\mathrm{ZnO}$ grain boundaries and metal Ag particles may lead to an increase of leakage current [76,77]. Organic NWs have the following advantages such as easy to design molecules to tune electronic properties and realize largescale synthesis at low cost, well flexibility and light weights $[78,79]$. They are also promising blockings for flexible electronic and optoelectronic devices [80,81]. Min et al. [82] use an organic NW printer to fabricate well-aligned P3HTPEO NWs with high-speed, to form an FET on $100 \mathrm{~nm} \mathrm{Au}$ with bottom gate design. Transfer characteristics of P3HTNW FET with $30 \%$ PEO at different numbers of wires are shown in Fig. 9d, which demonstrates a p-type characteristic. The maximal on-current increases as the number of NWs increases. Furthermore, this technique can be used to fabricate nano-channel transistors by printing another poly(9-vinyl carbazole) (PVK) NWAs followed a sonicating or adhesive tapes detaching process. Fig. 9e shows a p-type
FET properties and a short channel effect [83]. Certainly, this technique is very convenient to fabricate a large-area $\mathrm{NW}$ transistor array on rigid or flexible substrate such as wafer or flexible plastic as shown in inset of Fig. 9f. The average mobility of FET is $3.8 \pm 1.6 \mathrm{~cm}^{2} \mathrm{~V}^{-1} \mathrm{~s}^{-1}$ ( 100 devices), suggesting the promising future for mass production.

\section{Gas sensor}

Compared with disordered NW films, NWAs have a much large specific surface area as to the straight and parallel morphology. Nano-aligned fiber arrays will demonstrate a higher sensitivity [84]. Hollow ZnO NWAs were obtained via removing polyvinyl-acetate (PVAc) inside the composites [58]. SEM images of the as-spun PVAc fibers are shown in Fig. 10a.

The left is the randomly distributed PVAc NWs, the right is the aligned arrays, inset in the right shows that the NWs are hollow structured, and diameter is about 500-600 $\mathrm{nm}$. As shown in Fig. 10b, the quasi-aligned NWAs have a 2-fold higher sensitivity for $\mathrm{NO}_{2}$ compared with random fibers. And this enhancement is also demonstrated at different concentrations (2, 4, 6, 8, 10 ppm, respectively). This work was followed by Liu et al. [85]. They adopted 

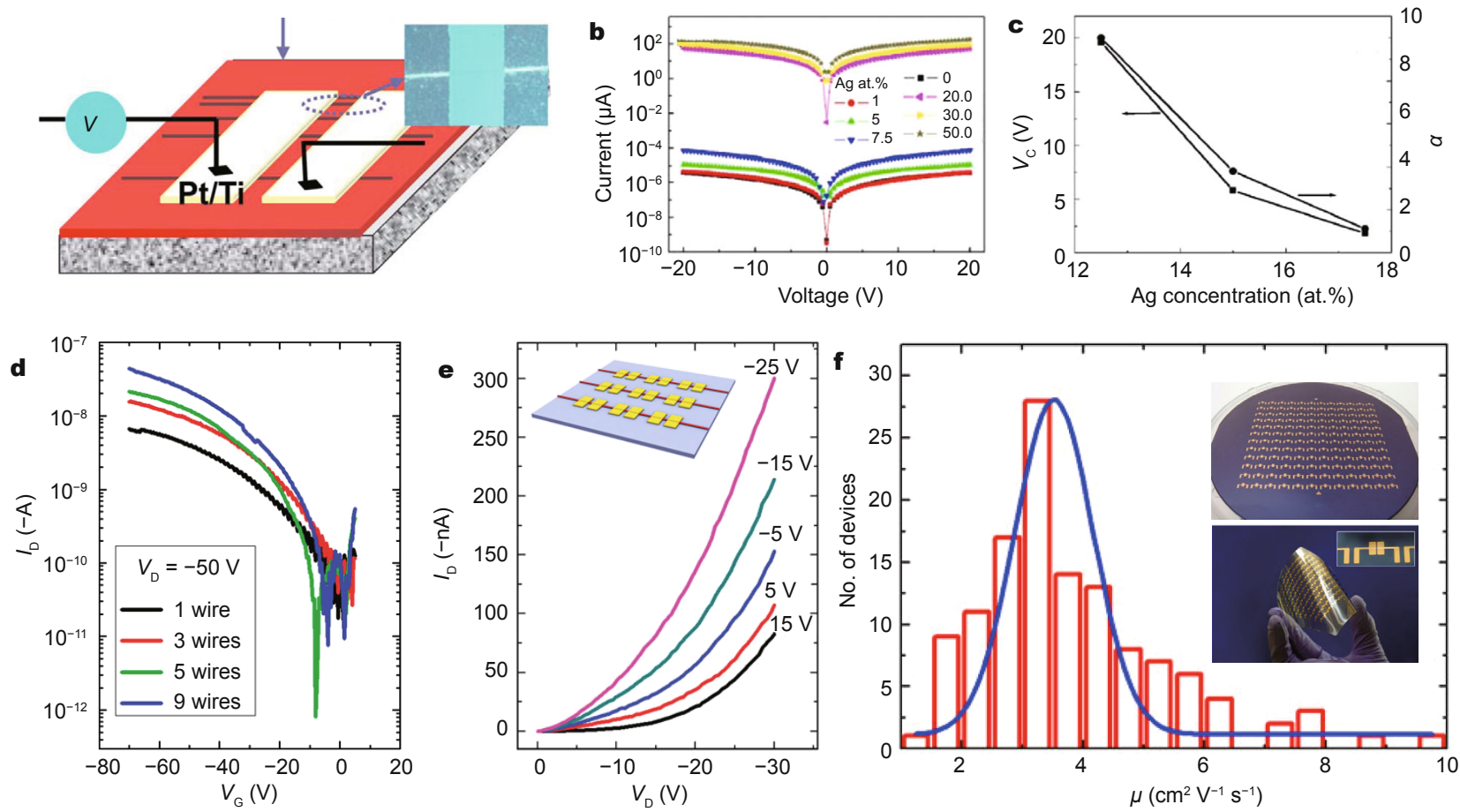

Figure 9 Application for electronics. (a) Diagram for the Ag-ZnO NWA device. (b) $I$ - $V$ characterization of the NWA. (c) $I$ - $V$ properties at different content of Ag. Reprinted with permission from Ref. [75] (Copyright 2009, American Institute of Physics). (d) Organic FET of P3HT blend NW FET with $30 \%$ PEO. (e) Output characteristics $\left(I_{\mathrm{d}}-V_{\mathrm{d}}\right)$ of P3HT blend NW FET with nanochannel length. (f) Histogram of the mobility for large-area P3HT:PEOblend NW FET array. Reprinted with permission from Ref. [82] (Copyright 2013, Nature Publishing Group).

the same fabrication path and obtained $\mathrm{ZnO}$ nanotubes array as shown in Fig. 10d. Furthermore, they investigated the response for $100 \mathrm{ppm}_{2}$ at different temperatures (Fig. 10e.) The sensitivity of $\mathrm{ZnO}$ nanotubes sensor for $100 \mathrm{ppm}$ $\mathrm{N}_{2}$ increases from 2.3 to 3.6 when the temperature increases from 200 to $400^{\circ} \mathrm{C}$.

\section{Piezoelectric sensor}

Semiconducting NWs with piezoelectric properties have attracted large research interest because of the potential application in converting mechanical strains into electricity [86]. Generally, nanomaterials used in mechanical energy scavenging include: film based [87], and NW-based piezoelectric sensor $[88,89]$. Two typical piezoelectric NWs are fabricated from lead zirconate titanate (PZT) or polyvinylidene fluoride (PVDF) by electrospinning [90,91]. PZT NWs prepared by an electrospinning process exhibit an extremely high piezoelectric voltage constant (g33, 0.079 $\mathrm{V} \mathrm{m} \mathrm{N}{ }^{-1}$ ), high bending flexibility, and high mechanical strength [92]. Chen et al. fabricated aligned PZT NWs by depositing the NWs on the prepared electrodes using interdigitated platinum fine wire arrays, the bottom substrate is silicon. A layer of polydimethylsiloxane (PDMS) is used to transport applied pressure. Extraction electrodes to an ex- ternal circuit are connected to the Pt electrodes as shown in Fig. 11a. The generated positive and negative voltage is induced by the transient flow of electrons when external load is on and removed [93]. Furthermore, the voltage is related to the pressure which is applied on the piezoelectric sensor surface as demonstrated in Fig. 11b. However, in order to obtain a good piezoelectric property, a high temperature annealing $\left(600^{\circ} \mathrm{C}\right)$ process for PZT NWs is generally required [94].

PVDF NWs may be a perfect candidate in wearable or implantable devices as to the combination of material properties in lightweight and flexibility [95]. Persano et al. [91] utilize the high speed rotating disk to obtain aligned PVDF NWAs in which the length of NWs can reach several centimeters. Interestingly, mesoscopic joints with hundreds of nanometers are formed between overlapping fibers which will enhance the mechanical robustness. The schematic illustration of an analytical model for the response of arrays of $\mathrm{P}(\mathrm{VDF}-\mathrm{TrFe})$ fibers is shown in Fig. 11c, inset is the photograph for applying pressure. Piezoelectric effect for different effective lengths is investigated as shown in Fig. $11 \mathrm{~d}$. The voltage is increased as the pressure increases with a linear relationship. Moreover, the response slops, defined as sensitivity, also increases as the effective length increas- 


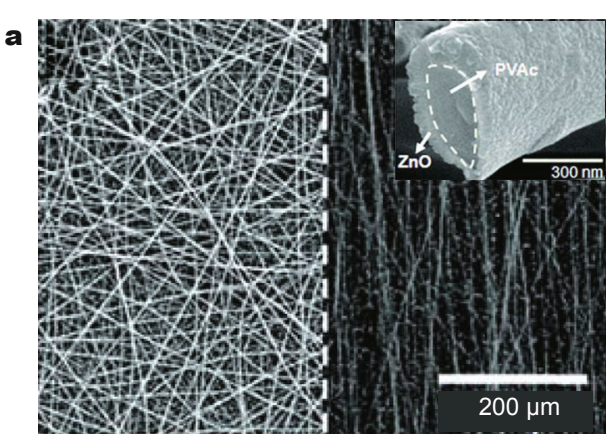

b
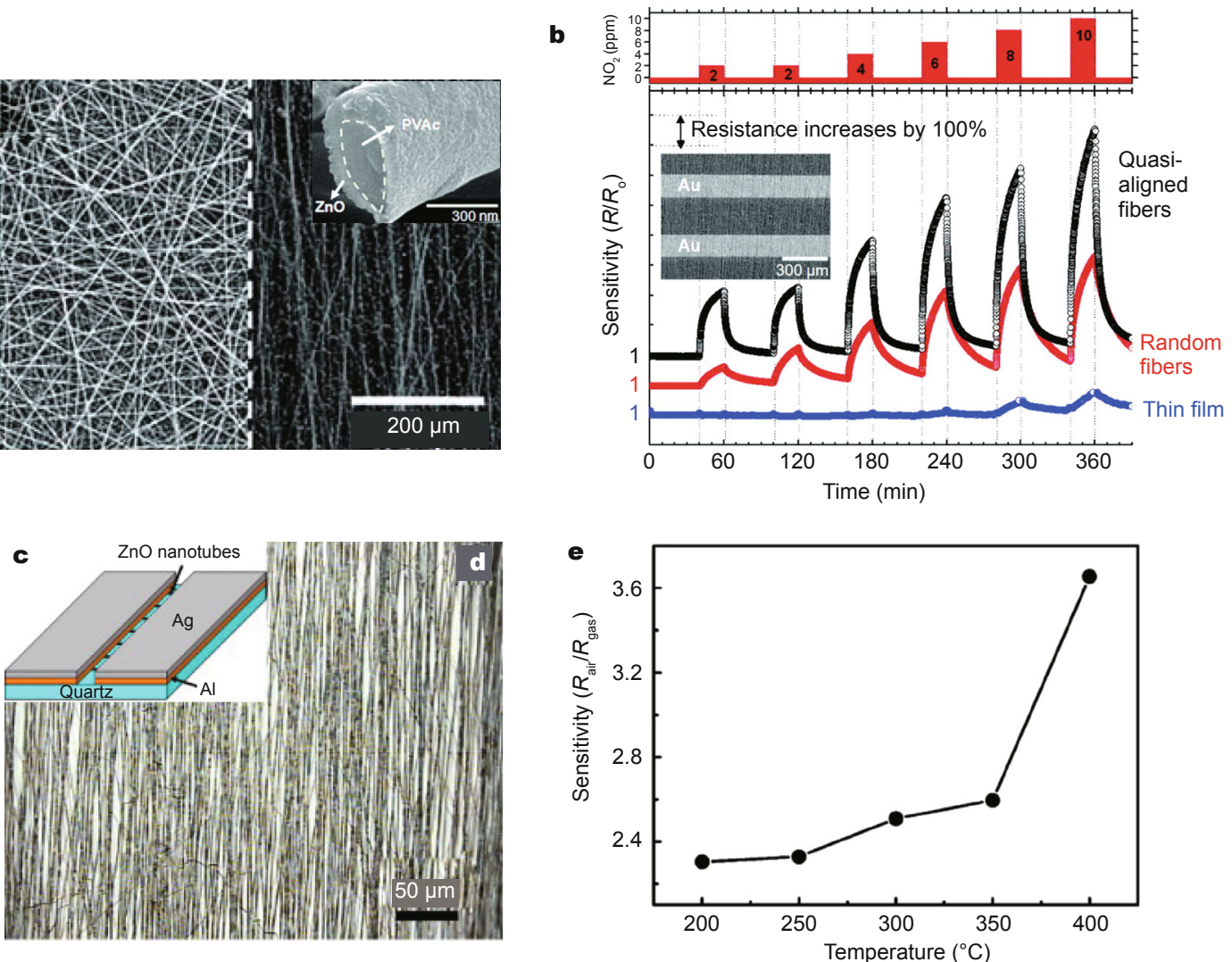

Figure 10 Application for gas sensors. (a) SEM images for the hollow ZnO films and arrays. (b) Acetone sensitivity for thin film devices, random fiber and quasi aligned fibers. Reprinted with permission from Ref. [58] (Copyright 2009, American Chemical Society). (c and d) Photograph for hollow ZnO NWA and device schematic diagram. (e) Sensitivity at different temperatures. Reprinted with permission from Ref. [85] (Copyright 2011, Elsevier).

es from 3 to $6 \mathrm{~mm}$. Theoretical pressure response consists with the experimental results at the effective length of $6 \mathrm{~mm}$.

\section{Photodetector}

As mentioned above, electrospinning is a facile way to mass-produce aligned NWAs, and photodetectors based on NWA demonstrate a high photoconductivity and fast response speed compared with randomly oriented NW films [96-100].

\section{Photodetector based on inorganic NWA}

1D inorganic NWA have been extensively studied and used to fabricate high-performance optoelectronic devices due to the large surface to volume ratios and granular morphology $[2,101]$.

Liu et al. [102] reported a full printing method to obtain $\mathrm{ZnO}$ NWA devices. Parallel arrays of NWs are formed on polyimide substrate when coupled with a programmable step motion as shown in inset of Fig. 12a. The number and the density of the $\mathrm{ZnO}$ NWs are tunable via adjusting the channel length of the electrodes. Taking five NWAs device as example, photocurrent at wavelength ranging from 300-800 nm demonstrates four orders of magnitudes selectivity higher for $365 \mathrm{~nm}$ than for $600 \mathrm{~nm}$ wavelength which is attractive for practical UV sensing (Fig. 12b) [103]. Much more details are shown in Fig. 12c. It can be seen that the responsivity is up to a level of $7.5 \times 10^{6} \mathrm{~A} \mathrm{~W}^{-1}$. This means that a low optical input can lead to a high photocurrent. In addition, the detectivity is as high as $10^{17}$ Jones which may due to the high photocurrent and low dark current at the same time. Generally electrospun NWs have larger surface area than commonly grown/synthesized NWs because of the rough surface and porous structure induced during the sintering process. Furthermore, grain boundaries lead to energy barriers that may block the carrier transport and introduce the additional band-edge modulation along axial direction which lead to a much lower dark current [104]. Carriers can easily pass through this axial energy barriers at the grain boundaries because the barrier height is low at the illumination of UV light. Further, this process is expected to be much faster than the oxygen adsorption/ 

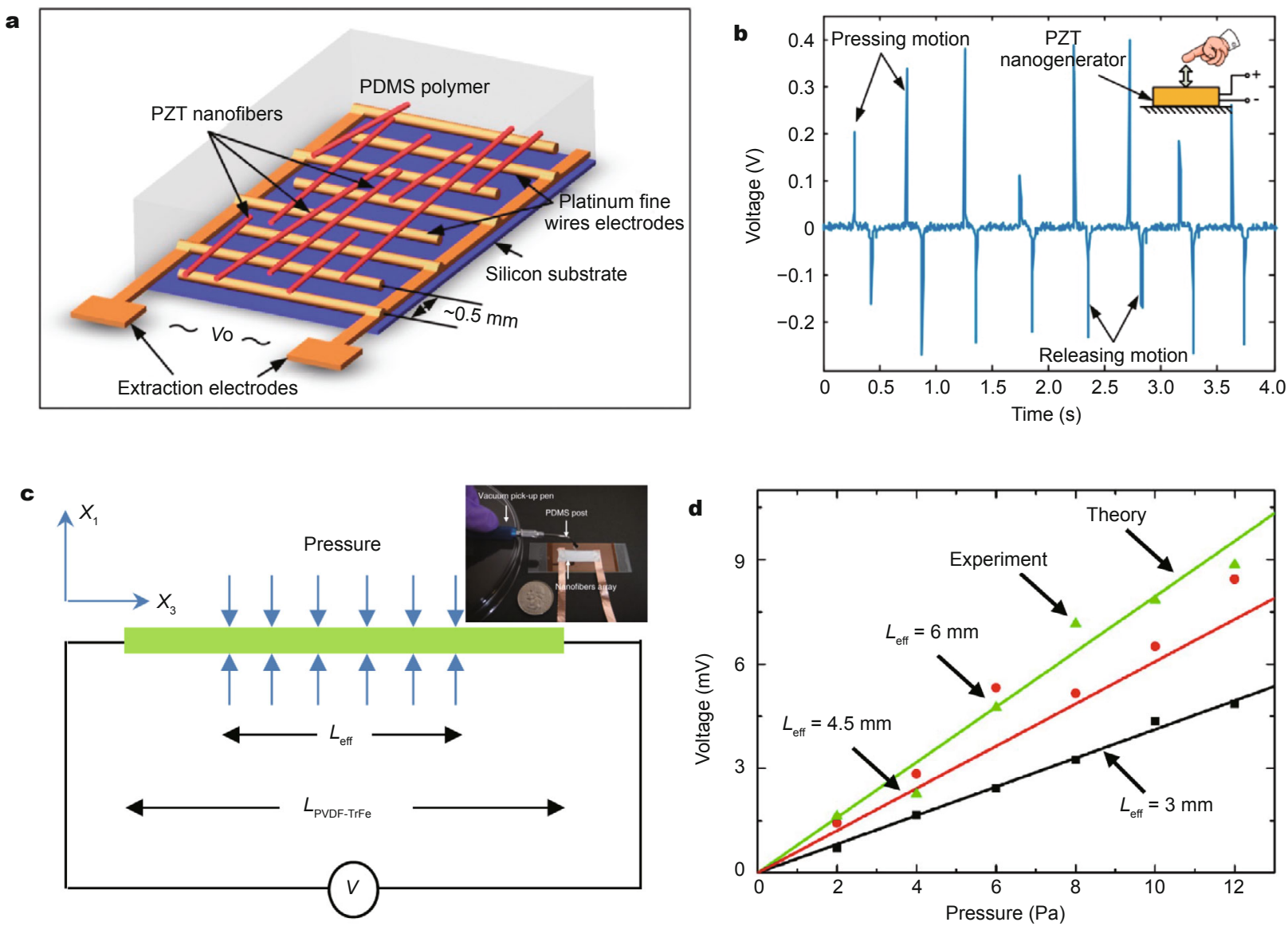

Figure 11 Application for piezoelectric sensors. (a) Schematic view of the PZT NW generator. (b) Voltage output measured when using a finger to apply a dynamic load on the top of the generator. Reprinted with permission from Ref. [90] (Copyright 2010, American Chemical Society). (c) Schematic illustration of an analytical model for the response of arrays of $\mathrm{P}(\mathrm{VDF}-\mathrm{TrFe})$ fibers, inset is the manipulator for applying pressure. (d) Voltage $v s$. pressure at different effective length. Reprinted with permission from Ref. [91] (Copyright 2013, Nature Publishing Group).

desorption process which leads to a fast response. Based on the results above, our group fused cadmium oxide into zinc oxide NW to broaden the spectral response range of $\mathrm{ZnO}$ from UV to visible light [105]. The UV-vis absorption curve of $\mathrm{ZnO}-\mathrm{CdO}$ hybrid NWs exhibits a mixture of individual $\mathrm{ZnO}$ and $\mathrm{CdO}$ NWs absorption curves as shown in Fig. 12d. The appearance of peak at $\sim 550 \mathrm{~nm}$ identifies the existence of $\mathrm{CdO}$ in hybrid NW. Moreover, a flexible photodetector with high transparence of $95 \%$ was fabricated on mica substrate (Fig. 12e) to verify the good flexibility of hybrid NWs (Fig. 12f).

\section{Photodetector based on heterostructures NWA}

Heterostructures which could lead to spatial separation of the photo-generated carriers, are designed to improve the photoelectric properties [106].

Huang et al. [107] combine the spin-coating with electrospinning techniques to obtain $\mathrm{p}$-type $\mathrm{NiO}$ films/n-type
$\mathrm{SnO}_{2} \mathrm{NW}$ heterojunction as shown in the schematic inset in Fig. 13a. Here, this heterojunction photodiode demonstrates a photosensitivity of up to $10^{5}$ at $-10 \mathrm{~V}$. This result is 100 times higher than that of the previous $\mathrm{SnO}_{2}$ nanobelts photodetector [108]. This enhanced UV photoresponse is much obvious in the reverse bias region as shown in Fig. $13 \mathrm{~b}$. At a reverse bias of $5 \mathrm{~V}$, the photoresponse curve record presents a more rectangular profile than the one at a forward bias of $5 \mathrm{~V}$. Response time at $-5 \mathrm{~V}$ is $10-20 \mathrm{~s}$ which is shorter than that in the $5 \mathrm{~V}$ bias. This improvement can also demonstrate that it is effective at the interface of inorganic-organic structure [109]. Aligned $\mathrm{TiO}_{2}$ NWAs as an interfacial electron collection layer were inserted into the thieno[3,4-b]thiophene/benzodithiophene (PTB7) and [6,6]phenyl C71-butyric acid by Nie et al. Device architecture is shown in Fig. 13c. The organic-based photodetectors (OPDs) with one-way aligned metal oxide NWs (AMONs) of $\mathrm{TiO}_{2}$ demonstrate a high detectivity of $10^{13}$ Jones in a 

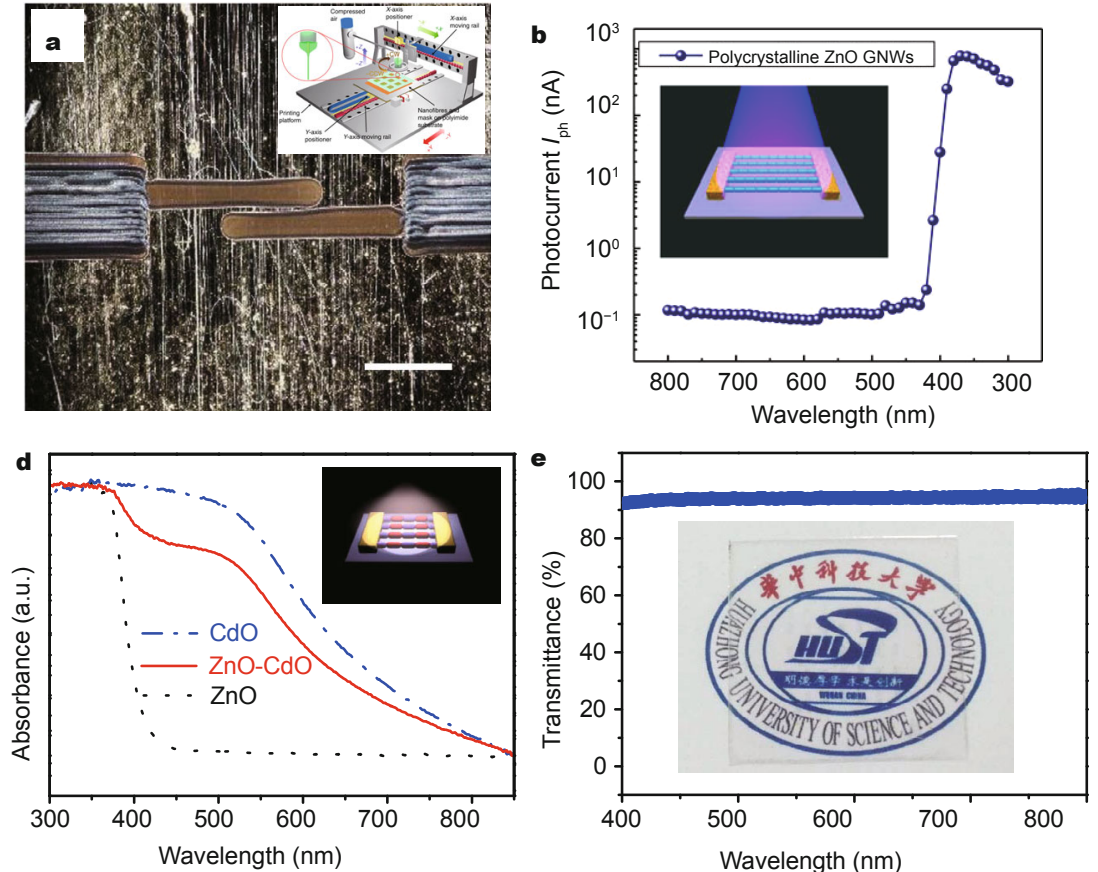
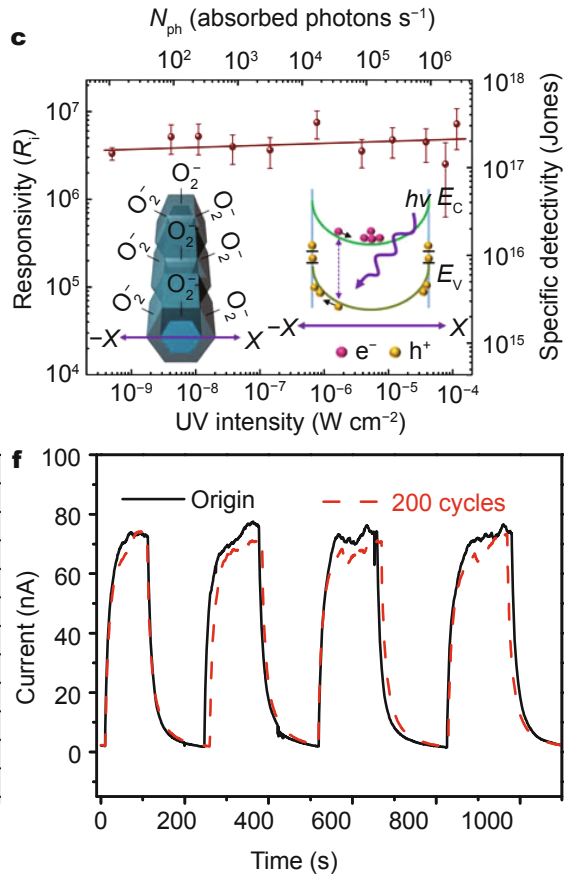

Figure 12 Application for photodetectors. (a) Photograph of device, inset is the schematic diagram of printing set-up. (b) Photocurrent with wavelength ranging from 300 to $800 \mathrm{~nm}$. (c) The corresponding responsivity and specific detectivity of the GNW photodetector. Reprinted with permission from Ref. [102] (Copyright 2014, Nature Publishing Group). (d) Photoresponse at different wavelengths. (e) Transmittance at different wavelength, inset: HUST logo covered by the as-fabricated photodetector. (f) Current-time curve between the original sample and the sample subjected to 200 bending cycles. Reprinted with permission from Ref. [105] (Copyright 2015, Wiley-VCH Publishers, Inc).

wide absorption range from 440 to $760 \mathrm{~nm}$ which is 10 times higher than that of the OPDs. In addition, the devices with one-way AMONs have a shorter response time and better stability than that without AMONs (Fig. 13d). No obvious change is observed in response time for devices with one-way AMONs of $\mathrm{TiO}_{2}$ even after $10^{10}$ times of electrically read up, while for the OPDs, the stability decreases a lot when read $10^{8}$ times. The reason may be that separated carriers will form at the inorganic-organic interface which could facilitate the charge transport which leads to the fast response speed [110]. In summary, these heterostructures provide innovative device architectures that enable high performance and broad-band spectral response.

\section{Humidity assisted photodetector}

Oxygen plays an important role in UV photoresponse of NWs, and this principle is also suitable to NWAs [111]. However, the environmental condition such as relative humidity $(\mathrm{RH})$ can influence the adsorption and desorption process of oxygen on the NW surface $[112,113]$. This influence was reflected on the response time and response speed as Lai et al. [113] investigated. Fig. 14a shows the response of $\mathrm{ZnO}$ nanowire at different humidity in the dark and UV illumination, respectively. In the dark, the response increases slowly at $\mathrm{RH}$ lower than 50\%; however, this response increases quickly when $\mathrm{RH}$ is over $50 \%$. Upon UV illumination, humidity influences the response obviously. This response increases from 1000 to 2000 when the $\mathrm{RH}$ increases from $10 \%$ to $57 \%$. However, the response decreases quickly when the humidity is over than $57 \%$. The rise and decay time of UV response is shown in Fig. 14b. As the humidity increases, the rise time decreases slowly from $26.7 \mathrm{~s}$ to $10.6 \mathrm{~s}$, while the decay speed may be three times quicker at RH of $81 \%$ compared with that at $10 \% \mathrm{RH}$. Our group attempted to construct $\mathrm{ZnO}-\mathrm{CdO}$ hybrid NWAs based humidity sensors [105]. The photocurrent decreases as the humidity increases and photoresponse increases first and then decreases when the humidity is ranging from $10 \%$ to $70 \%$ as shown in Fig. 14c. The adsorption/ desorption of surface species and carrier transport process in the dry air and high RH condition is shown in Fig. 14d. At low $\mathrm{RH}, \mathrm{H}_{2} \mathrm{O}$ molecules replace original ionized oxygen and distribute independently. Therefore, the released electrons by the oxygen ions will contribute to the conductivity in the dark when the $\mathrm{RH}$ is low. The water may gradually form a monolayer on the NW surface when the RH is high and leads to a water dissociation process. The conductivity will have a sharp increase because the $\mathrm{H}^{+}$and $\mathrm{OH}^{-}$can pro- 

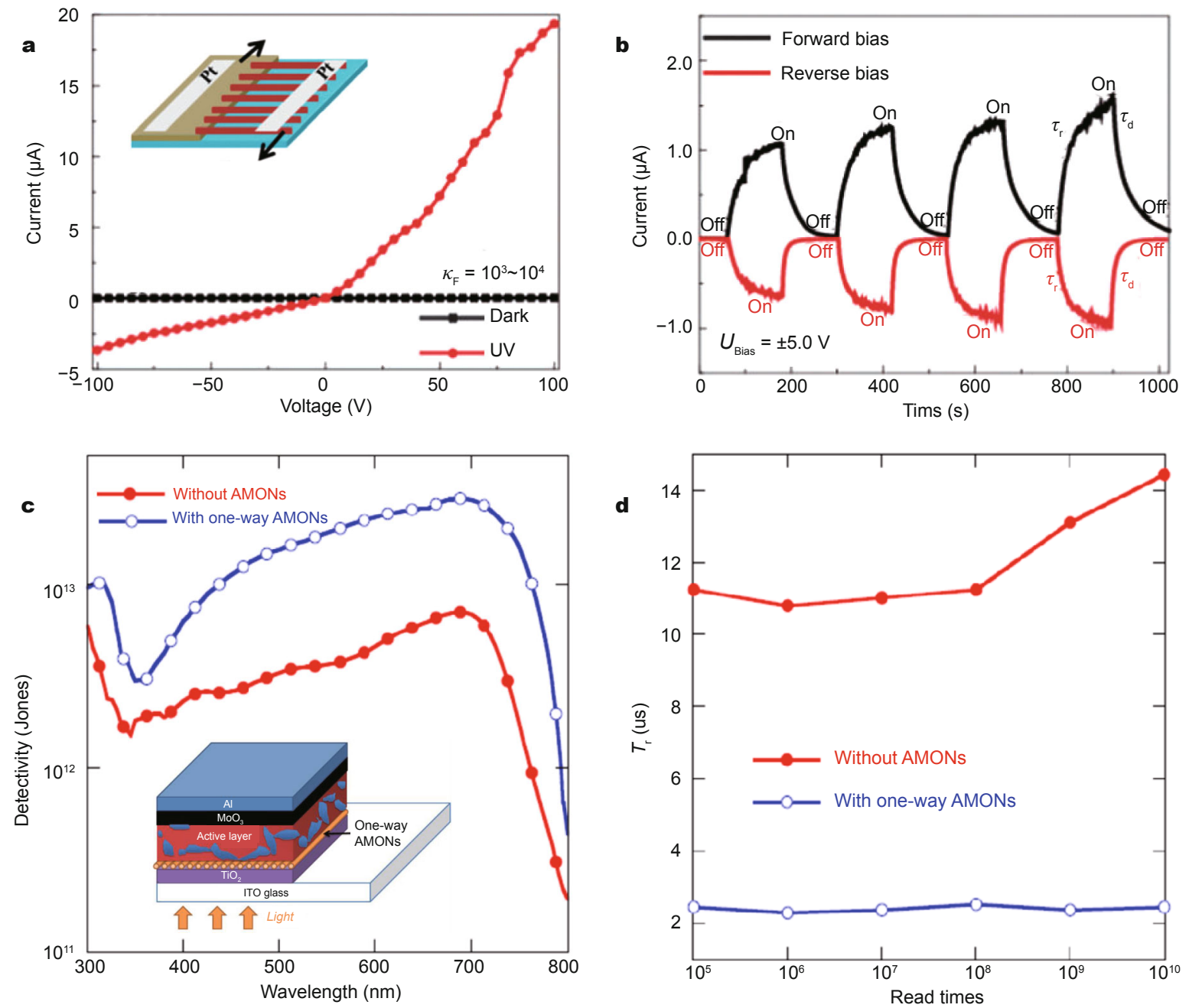

Figure 13 Application for photodetectors with heterojunction. (a) $I$ - $V$ curve at UV light. (b) $I$ - $t$ curve measured under forward and reverse bias conditions, respectively. Reprinted with permission from Ref. [107] (Copyright 2014, Royal Society of Chemistry). (c) Detectivity at different wavelength with $\mathrm{TiO}_{2}$ array or without $\mathrm{TiO}_{2}$ NWA. (d) Response time without $\mathrm{AMONs}$ of $\mathrm{TiO}_{2}$ or with one-way AMONs of TiO $\mathrm{Am}_{2}$. Reprinted with permission from Ref. [109] (Copyright 2013, American Chemical Society).

vide ionic conductivity. When the UV light is on under the dry air, photo-generated holes will combine with oxygen ion, increase of conductivity is induced by the remaining photo-generated electrons. However, when the UV light is on under high $\mathrm{RH}$ air, the dissociated $\mathrm{H}_{2} \mathrm{O}$ molecules will capture electron and hole at the same time, which leads to a low density of carriers, quick recombination and subsequently fast photocurrent decay will occur when the UV light is switched off [114].

\section{CONCLUSIONS}

In this review, we made a concise retrospection on reported assembling methods for NWs, and primarily highlighted the importance of electrospinning method for NW fabri- cation and alignment as well as the substantial improvement of this method, such as field assisted method, rotating collector assisted method and near-field assisted method. Highly ordered NW structures showed improvements in various areas of electronics and optoelectronics including flexible electrodes, FET, sensors, as well as photodetectors, which also pave the way for future development of high integration density circuits.

However, there are also some deficiencies of electrospinning method needed to be improved. Field assisted method cannot precisely control the number of electrospun NWs; rotating collector assisted method has a problem of low-quality alignment; near field assisted method is not suitable for mass production. Moreover, the kinds of 

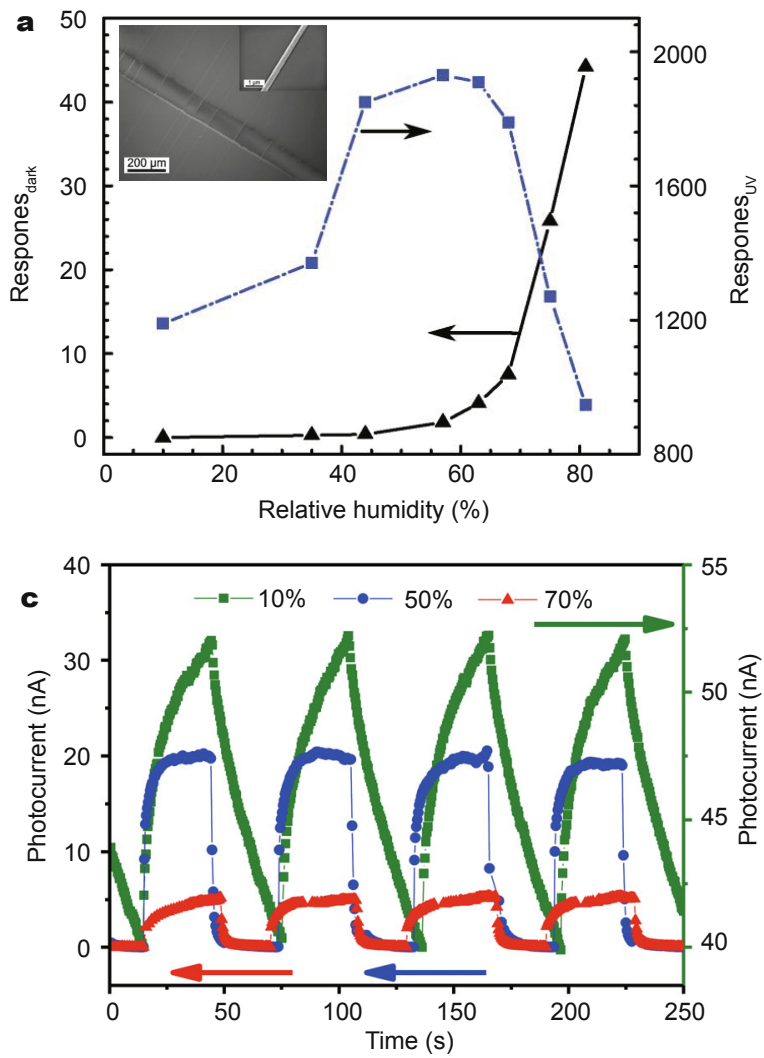

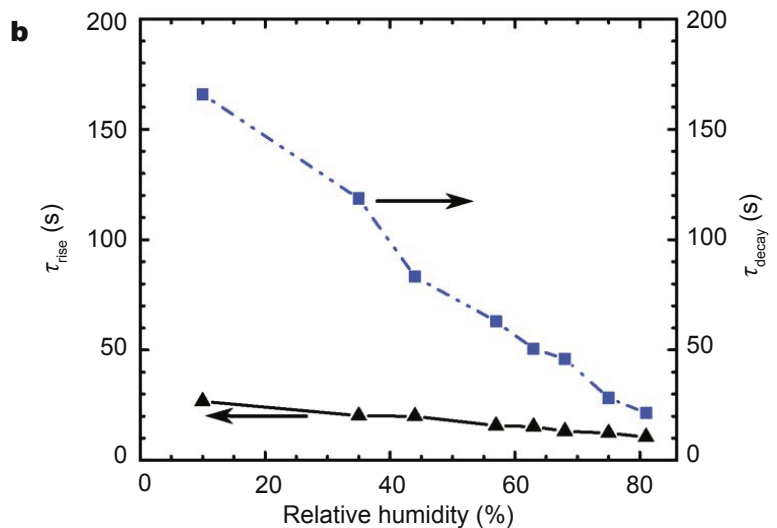

d
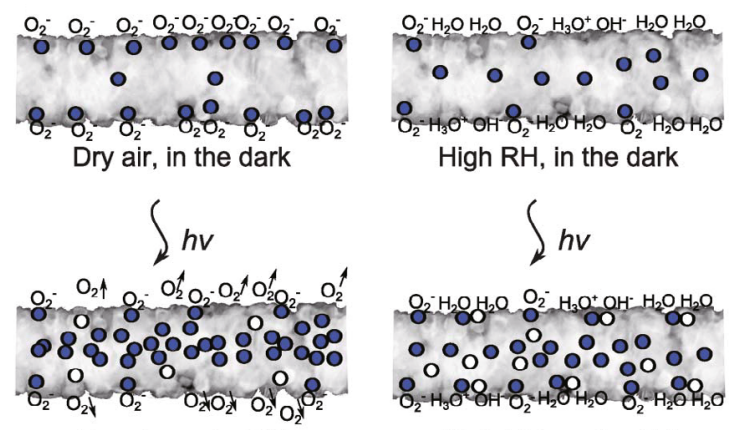

Dry air, under UV
High RH, in the dark

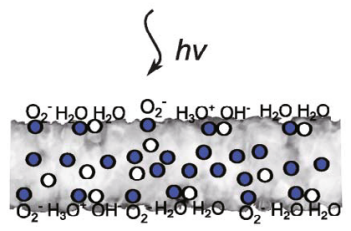

High $\mathrm{RH}$, under UV

Figure 14 Application for photodetectors at assist of humidity. (a) The response of the ZnO nanowire device in the dark or under UV illumination upon exposure to the air with different RH levels. Inset is SEM images of the device. (b) Rise and decay time at different humidity. (c) Photoresponse at different humidity. Reprinted with permission from Ref. [113] (Copyright 2015, Wiley-VCH Publishers, Inc). (d) Mechanism for low humidity and high humidity. Reprinted with permission from Ref. [105] (Copyright 2013, Royal Society of Chemistry).

conductive polymer which suit for electrospinning are still rare, while for insulating polymers generally high temperature are required to remove them before utilization which would result in deformation of NWAs. Therefore, there is still giant room for improving the electrospinning method both in technique and materials choice. As for technique, we consider the alignment quality and mass production are the main issues in the future, which finally decides the potential of practical application. With regards to materials choice, we hold the opinion that hybrid and complementary materials are the future researching hot spots, which can be fabricated into specific morphologies like core-shell to extend the application field of devices.

Received 25 Feburary 2016; accepted 22 March 2016; published online 30 March 2016

1 Zhai T, Yao J. One-Dimensional Nanostructures: Principles and Applications. New Jersy: John Wiley \& Sons Hoboken, 2013

2 Zhai TY, Li L, Wang X, et al. Recent developments in one-dimensional inorganic nanostructures for photodetectors. Adv Funct Ma- ter, 2010, 20: 4233-4248

3 Xia YN, Yang PD, Sun YG, et al. One-dimensional nanostructure: synthesis, characterization, and applications. Adv Mater, 2003, 15: 353-389

4 Liu JW, Liang HW, Yu SH. Macroscopic-scale assembled nanowire thin films and their functionalities. Chem Rev, 2012, 112: 4770-4799

5 Greiner A, Wendorff JH. Electrospinning: a fascinating method for the preparation of ultrathin fibers. Angew Chem Int Ed, 2007, 46: 5670-5703

6 Li D, Xia YN. Electrospinning of nanofibers: reinventing the wheel? Adv Mater, 2004, 16: 1151-1170

7 Zhou SS, Chen JN, Gan L, et al. Scalcable production of self-supported $\mathrm{WS}_{2} / \mathrm{C}$ nanofibers by electrospinning as the anode for high performance lithium-ion batteries. Sci Bull, 2016, 61: 227-235

8 Elnathan R, Kwiat M, Patolsky F, Voelcker NH. Engineering vertically aligned semiconductor nanowire arrays for applications in the life sciences. Nano Today, 2014, 9: 172-196

9 Li Y, Duan GT, Liu GQ, Cai WP. Physical processes-aided periodic micro/nanostructured arrays by colloidal template technique: fabrication and applications. Chem Soc Rev, 2013, 42: 3614-3627

10 Huang ZP, Geyer N, Werner P, Boor JD, Gösele U. Metal-assisted chemical etching of silicon: a review. Adv Mater, 2011, 23: 285-308

11 Yu GH, Cao A, Lieber CM. Large-area blown bubble films of aligned 
NWs and carbon nanotubes. Nat Nanotechnol, 2007, 2: 372-377

12 Li D, Wang YL, Xia YN. Electrospinning of polymeric and ceramic nanofibers as uniaxially aligned arrays. Nano Lett, 2003, 3: 1167-1171

13 Pan ZW, Dai ZR, Wang ZL. Nanobelts of semiconducting oxides. Science, 291: 1947-1949

14 Gudiksen MS, Lauhon LJ, Wang JF, Smith DC, Lieber CM. Growth of nanowire superlattice structures for nanoscale photonics and electronics. Nature, 2002, 415: 617-620

15 Lee HW, Muralidharan P, Ruffo R, et al. Ultrathin spinel $\mathrm{LiMn}_{2} \mathrm{O}_{4}$ NWs as high power cathode materials for Li-ion batteries. Nano Lett, 2010, 10: 3852-3856

16 Limmer SJ, Cao G. Sol-gel electrophoretic deposition for the growth of oxide nanorods. Adv Mater, 2003, 15: 427-431

17 Li ZY, Zhang HN, Zheng W. Highly sensitive and stable humidity nanosensors based on $\mathrm{LiCl}$ doped $\mathrm{TiO}_{2}$ electrospun nanofibers. J Am Chem Soc, 2008, 130: 5036-5037

18 Long YZ, Yu M, Sun B, Gu CZ, Fan ZY. Recent advances in largescale assembly of semiconducting inorganic NWs and nanofibers for electronics, sensors and photovoltaics. Chem Soc Rev, 2012, 41: 4560-4580

19 Yang PD. Wires on water. Nature, 2003, 425: 243-244

20 Whang D, Jin S, Wu Y, Lieber CM. Large-scale hierarchical organization of nanowire arrays for integrated nanosystems. Nano Lett, 2003, 3: 1255-1259

21 Liu JW, Wang JL, Huang WR, et al. Ordering Ag nanowire arrays by a glass capillary: a portable, reusable and durable SERS substrate. Sci Rep, 2012, 2: 987

22 Wang DW, Chang YL, Liu Z, Dai HJ. Oxidation resistant germanium NWs: bulk synthesis, long chain alkanethiol functionalization, and Langmuir-Blodgett assembly. J Am Chem Soc, 2005, 127: 11871-11875

23 Kim YK, Kim DI, Park J. Facile transfer of thickness controllable poly(methyl methacrylate) patterns on a nanometer scale onto $\mathrm{SiO}_{2}$ substrates via microcontact printing combined with simplified langmuir-schaefer technique. Langmuir, 2008, 24: 14289-14295

24 Acharya S, Panda AB, Belman N, Efrima S, Golan Y. A semiconductor-nanowire assembly of ultrahigh junction density by the Langmuir-Blodgett technique. Adv Mater, 2006, 18: 210-213

25 Patla I, Acharya S, Zeiri L, et al. Synthesis, two-dimensional assembly, and surface pressure-induced coalescence of ultranarrow $\mathrm{PbS}$ NWs. Nano Lett, 2007, 7: 1459-1462

26 Kim F, Kwan S, Akana J, Yang PD. Langmuir-Blodgett nanorod assembly. J Am Chem Soc, 2001, 123: 4360-4361

27 Yu GH, Li XL, Lieber CM, Cao AY. Nanomaterial-incorporated blown bubble films for large-area, aligned nanostructures. J Mater Chem, 2008, 18: 728-734

28 Lee M, Im J, Lee BY, et al. Linker-free directed assembly of high-performance integrated devices based on nanotubes and NWs. Nat Nanotechnol, 2006, 1: 66-71

29 Heo K, Cho E, Yang JE, et al. Large-scale assembly of silicon nanowire network-based devices using conventional microfabrication facilities. Nano Lett, 2008, 8: 4523-4527

30 Rao SG, Huang L, Setyawan W, Hong S. Nanotube electronics: large-scale assembly of carbon nanotubes. Nature, 2003, 425: 36-37

31 Fan ZY, Ho JC, Takahashi T, et al. Toward the development of printable nanowire electronics and sensors. Adv Mater, 2009, 21: 3730-3743

32 Fan ZY, Ho JC, Jacobson ZA, et al. Wafer-scale assembly of highly ordered semiconductor nanowire arrays by contact printing. Nano Lett, 2008, 8: 20-25

33 Yao J, Yan H, Lieber CM. A nanoscale combing technique for the large-scale assembly of highly aligned NWs. Nat Nanotechnol,
2013, 8: 329-335

34 Yerushalmi R, Jacobson ZA, Ho JC, Fan ZY, Javey A. Large scale, highly ordered assembly of nanowire parallel arrays by differential roll printing. Appl Phys Lett, 2007, 91: 203104

35 Chen G, Liu Z, Liang B, et al. Single-crystalline p-type $\mathrm{Zn}_{3} \mathrm{As}_{2} \mathrm{NWs}$ for field-effect transistors and visible-light photodetectors on rigid and flexible substrates. Adv Funct Mater, 2013, 23: 2681-2690

36 Chen G, Liang B, Liu Z, et al. High performance rigid and flexible visible-light photodetectors based on aligned X(In, Ga)P nanowire arrays. J Mater Chem C, 2014, 2: 1270-1277

37 Fan ZY, Ho JC, Takahashi T, et al. Toward the development of printable nanowire electronics and sensors. Adv Mater, 2009, 21: 3730-3743

38 Fan ZY, Ho JC, Jacobson ZA, et al. Wafer-scale assembly of highly ordered semiconductor nanowire arrays by contact printing. Nano Lett, 2008, 8: 20-25

39 Lau PH, Takei K, Wang C, et al. Fully printed, high performance carbon nanotube thin-film transistors on flexible substrates. Nano Lett, 2013, 13: 3864-3869

40 Dong LF, Bush J, Chirayos V, Solanki R, Jiao J. Dielectrophoretically controlled fabrication of single-crystal nickel silicide nanowire interconnects. Nano Lett, 2005, 5: 2112-2115

41 Salem AK, Chao J, Leong KW, Searson PC. Receptor-mediated self-assembly of multi-component magnetic NWs. Adv Mater, 16: 268-271

42 Lee CH, Kim DR, Zheng XL. Orientation-controlled alignment of axially modulated pn silicon NWs. Nano Lett, 2010, 10: 5116-5122

43 Islam MS, Sharma S, Kamins TI, Williams RS. Ultrahigh-density silicon nanobridges formed between two vertical silicon surfaces. Nanotechnology, 2004, 15: L5-L8

44 Li YB, Paulsen A, Yamada I, Koide Y, Delaunay JJ. Bascule nanobridges self-assembled with $\mathrm{ZnO}$ NWs as double Schottky barrier UV switches. Nanotechnology, 2010, 21: 295502

45 Fortuna SA, Wen JG, Chun IS, Li XL. Planar GaAs NWs on GaAs (100) substrates: self-aligned, nearly twin-defect free, and transfer-printable. Nano Lett, 2008, 8: 4421-4427

46 Tsivion D, Schvartzman M, Biro RP, Joselevich E. Guided growth of horizontal $\mathrm{ZnO} \mathrm{NWs}$ with controlled orientations on flat and faceted sapphire surfaces. ACS Nano, 2012, 6: 6433-6445

47 Pevzner A, Engel Y, Elnathan R, et al. Confinement-guided shaping of semiconductor NWs and nanoribbons: "writing with NWs". Nano Lett, 2012, 12: 7-12

$48 \mathrm{Yu} \mathrm{LW}, \mathrm{Xu} \mathrm{MK}, \mathrm{Xu}$ J, et al. In-plane epitaxial growth of silicon NWs and junction formation on $\mathrm{Si}(100)$ substrates. Nano Lett, 2014, 14: 6469-6474

49 Bhardwaj N, Kundu SC. Electrospinning: a fascinating fiber fabrication technique. Biotechnol Adv, 2010, 28: 325-347

50 Loscertales IG, Barrero A, Guerrero I, et al. Micro/nano encapsulation via electrified coaxial liquid jets. Science, 2002, 295: 1695-1698

51 Li D, Wang YL, Xia YN. Electrospinning nanofibers as uniaxially aligned arrays and layer-by layer stacked films, Adv Mater, 2004, 16: 361-366

52 Xie J, Liu W, MacEwan MR, Bridgman PC, Xia Y. Neurite outgrowth on electrospun nanofibers with uniaxial alignment: the effects of fiber density, surface coating, and supporting substrate. ACS Nano, 2014, 8: 1878-1885

53 Wu H, Sun Y, Lin DD, et al. GaN nanofibers based on electrospinning: facile synthesis, controlled assembly, precise doping, and application as high performance UV photodetector. Adv Mater, 2009, 21: 227-231

54 Katta P, Alessandro M, Ramsier RD, Chase GG. Continuous electrospinning of aligned polymer nanofibers onto a wire drum collector. Nano Lett, 2004, 4: 2215-2218 
55 Matthews JA, Wnek GE, Simpson DG, Bowlin GL. Electrospinning of collagen nanofibers. Biomacromolecules, 2002, 3: 232-238

56 Pan H, Li L, Hu L, Cui XJ. Continuous aligned polymer fibers produced by a modified electrospinning method. Polymer, 2006, 47: 4901-4904

57 Li D, Xia YN. Direct fabrication of composite and ceramic hollow nanofibers by electrospinning. Nano Lett, 2004, 4: 933-938

58 Choi SH, Ankonina G, Youn DY, et al. Hollow $\mathrm{ZnO}$ nanofibers fabricated using electrospun polymer templates and their electronic transport properties. ACS Nano, 2009, 3: 2623-2631

59 Yang DY, Lu B, Zhao Y, Jiang X. Fabrication of aligned fibrous arrays by magnetic electrospinning. Adv Mater, 2007, 19: 3702-3706

60 Liu YQ, Zhang XP, Xia YN, Yang H. Magnetic-field-assisted electrospinning of aligned straight and wavy polymeric nanofibers. Adv Mater, 2010, 22: 2454-2457

61 Teo WE, Ramakrishna S. A review on electrospinning design and nanofiber assemblies. Nanotechnology, 2006, 17: R89-R106

62 Shim HS, Na SI, Nam SH, et al. Efficient photovoltaic device fashioned of highly aligned multilayers of electrospun $\mathrm{TiO}_{2}$ nanowire array with conjugated polymer. Appl Phys Lett, 2008, 92: 183107

63 Xua CY, Inaic R, Kotaki M, Ramakrishnaa S. Aligned biodegradable nanofibrous structure: a potential scaffold for blood vessel engineering. Biomaterials, 2004, 25: 877-886

64 Sundaray B, Subramanian V, Natarajan TS, et al. Electrospinning of continuous aligned polymer fibers. Appl Phys Lett, 2004, 84: 1222-1224

65 Theron A, Zussman E, Yarin AL. Electrostatic field-assisted alignment of electrospun nanofibers. Nanotechnology, 2001, 12: 384-390

66 Ding ZW, Salim A, Ziaie B. Selective nanofiber deposition through field-enhanced electrospinning. Langmuir, 2009, 25: 9648-9652

67 Zhang D, Chang J. Patterning of electrospun fibers using electroconductive templates. Adv Mater, 2007, 19: 3664-3667

68 Badrossamay MR, McIlwee HA, Goss JA, Parker KK. Nanofiber assembly by rotary jet-spinning. Nano Lett, 2010, 10: 2257-2261

69 Li MM, Long YZ, Yang DY, et al. Fabrication of one dimensional superfine polymer fibers by double-spinning. J Mater Chem, 2011, 21: 13159-13162

70 Khamforoush M, Mahjob M. Modification of the rotating jet method to generate highly aligned electrospun nanofibers. Mater Lett, 2011, 65: 453-455

71 Sun DH, Chang C, Li S, Lin LW. Near-field electrospinning. Nano Lett, 2006, 6: 839-842

72 Chang C, Tran VH, Wang JB, Fuh YK, Lin LW. Direct-write piezoelectric polymeric nanogenerator with high energy conversion efficiency. Nano Lett, 2010, 10: 726-731

73 Brown TD, Dalton PD, Hutmacher DW. Direct writing by way of melt electrospinning. Adv Mater, 2011, 23: 5651-5657

74 Bisht GS, Canton G, Mirsepassi A, et al. Controlled continuous patterning of polymeric nanofibers on three-dimensional substrates using low-voltage near-field electrospinning. Nano Lett, 2011, 11: 1831-1837

75 Lin DD, Wu H, Qin XL, Pan W. Electrical behavior of electrospun heterostructured Ag-ZnO nanofibers. Appl Phys Lett, 2009, 95: 112104

76 Duran P, Capel F, Tartaj J, Moure C. A strategic two-stage low-temperature thermal processing leading to fully dense and fine-grained doped-ZnO varistors. Adv Mater, 2002, 14: 137-141

77 Pham MTN, Boukamp BA, Bouwmeester HJM, Blank DHA. Microstructural and electrical properties of nanocomposite $\mathrm{PZT} / \mathrm{Pt}$ thin films made by pulsed laser deposition. Ceram Int, 2004, 30: 1499-1503

78 Li RJ, Hu WP, Liu YQ, Zhu D. Micro-and nanocrystals of organic semiconductors. Accounts Chem Res, 2010, 43: 529-540
79 Dong HL, Zhu HF, Meng Q, Gong X, Hu W. Organic photoresponse materials and devices. Chem Soc Rev, 2012, 41: 1754-1808

80 Brisenoa AL, Mannsfeldb SCB, Jenekhea SA, Baob Z, Xia YN. Introducing organic nanowire transistors. Mater today, 2008, 11: 38-47

81 Qiu LZ, Lee WH, Wang XH, et al. Organic thin-film transistors based on polythiophene NWs embedded in insulating polymer. Adv Mater, 2009, 21: 1349-1353

82 Min SY, Kim TS, Kim BJ, et al. Large-scale organic nanowire lithography and electronics. Nat Commun, 2013, 4: 1773

83 Liu SH, Tok JBH, Bao ZN. Nanowire lithography: fabricating controllable electrode gaps using Au-Ag-Au NWs. Nano Lett, 2005, 5: 1071-1076

84 Jin S, Whang D, McAlpine MC, et al. Scalable interconnection and integration of nanowire devices without registration. Nano Lett, 2004, 4: 915-919

85 Liu YX, Gao CT, Pan XJ, et al. Synthesis and $\mathrm{H}_{2}$ sensing properties of aligned ZnO nanotubes. Appl Surf Sci, 2011, 257: 2264-2268

86 Wang ZL, Song JH. Piezoelectric nanogenerators based on zinc oxide nanowire arrays. Science, 2006, 312: 242-246

87 Sun CL, Shi J, Bayerl DJ, et al. PVDF microbelts for harvesting energy from respiration. Energy Environ Sci, 2011, 4: 4508-4512

88 Kumar B, Kim SW. Recent advances in power generation through piezoelectric nanogenerators. J Mater Chem, 2011, 21: 18946-18958

89 Chang C, Tran VH, Wang JB, Fuh YK, Lin L. Direct-write piezoelectric polymeric nanogenerator with high energy conversion efficiency. Nano Lett, 2010, 10: 726-731

90 Chen X, Xu SY, Yao N, Shi Y. 1.6 V nanogenerator for mechanical energy harvesting using PZT nanofibers. Nano Lett, 2010, 10: 2133-2137

91 Persano L, Dagdeviren C, Su YW, et al. High performance piezoelectric devices based on aligned arrays of nanofibers of poly (vinylidenefluoride-co-trifluoroethylene). Nat Commun, 2013, 4:1633

92 Chen X, Xu SY, Yao N, Xu W, Shi Y. Potential measurement from a single lead ziroconate titanate nanofiber using a nanomanipulator. Appl Phys Lett, 2009, 94: 253113

93 Zhang Y, Liu Y, Wang ZL. Fundamental theory of piezotronics. Adv Mater, 2011, 23: 3004-3013

94 Xu SY, Shi Y, Kim SG. Fabrication and mechanical property of nano piezoelectric fibres. Nanotechnology, 2006, 17: 4497-4501

95 Chang J, Lin L. Large array electrospun PVDF nanogenerators on a flexible substrate. Proceedings of the 16th International Solid-State Sensors, Actuators and Microsystems Conference. IEEE, 2011, $747-750$

96 Xin Y, Huang ZH, Peng L, Wang DJ. Photoelectric performance of poly(p-phenylene vinylene) $/ \mathrm{Fe}_{3} \mathrm{O}_{4}$ nanofiber array. J Appl Phys, 2009, 105: 086106

97 Heo K, Lee H, Park Y, et al. Ligned networks of cadmium sulfide NWs for highly flexible photodetectors with improved photoconductive responses. J Mater Chem, 2012, 22: 2173

98 Singh A, Li XY, Protasenko V, et al. Polarization-sensitive nanowire photodetectors based on solution-synthesized CdSe quantum-wire solids. Nano Lett, 2007, 7: 2999-3006

99 Yu YH, Protasenko V, Jena D, Xing H, Kuno M. Photocurrent polarization anisotropy of randomly oriented nanowire networks. Nano Lett, 2008, 8: 1352-1357

100 Wu H, Sun Y, Lin DD, et al. GaN nanofibers based on electrospinning: facile synthesis, controlled assembly, precise doping, and application as high performance UV photodetector. Adv Mater, 2009, 21: 227-231

101 Kim CJ, Lee HS, Cho YJ, Kang K, Jo MH. Diameter-dependent internal gain in ohmic Ge nanowire photodetectors. Nano Lett, 2010, 10: $2043-2048$

102 Liu X, Gu LL, Zhang QP, et al. All-printable band-edge modulat- 
ed $\mathrm{ZnO}$ nanowire photodetectors with ultra-high detectivity. Nat Commun, 2014, 5: 4007

103 Lin CH, Chang SJ, Chen WS, Hsueh TJ. Transparent ZnO-nanowire-based device for UV light detection and ethanol gas sensing on c-Si solar cell. RSC Adv, 2016, 6: 11146

104 Hossain FM, Nishii J, Takagi S, et al. Modeling and simulation of polycrystalline $\mathrm{ZnO}$ thin-film transistors. J Appl Phys, 2003, 94: 7768-7777

105 Zheng Z, Gan L, Li HQ, et al. A fully transparent and flexible ultraviolet-visible photodetector based on controlled electrospun $\mathrm{ZnO}$ CdO heterojunction nanofiber arrays. Adv Funct Mater, 2015, 25: 5885-5894

106 Tian W, Zhai TY, Zhang C, et al. Low-cost fully transparent ultraviolet photodetectors based on electrospun $\mathrm{ZnO}-\mathrm{SnO}_{2}$ heterojunction nanofibers. Adv Mater, 2013, 25: 4625-4630

107 Huang SY, Wu H, Matsubara K, Cheng J, Pan W. Facile assembly of $\mathrm{n}-\mathrm{SnO}_{2}$ nanobelts-p- $\mathrm{NiO}$ heterojunctions with enhanced ultraviolet photoresponse. Chem Commun, 2014, 50: 2847-2850

108 Huang SY, Wu H, Zhou M, et al. A flexible and transparent ceramic nanobelt network for soft electronics. NPG Asia Mater, 2014, 6: e86

109 Nie R, Wang YY, Deng XY. Aligned nanofibers as an interfacial layer for achieving high detectivity and fast-response organic photodetectors. ACS Appl Mater Interfaces, 2014, 6: 7032-7037

110 Deng MJ, Shen SL, Wang XW, et al. Controlled synthesis of AgInS nanocrystals and their application in organic-inorganic hybrid photodetectors. CrystEngComm, 2013, 15: 6443-6447
111 Kind H, Yan HQ, Messer B, Law M, Yang PD. Nanowire ultraviolet photodetectors and optical switches. Adv Mater, 2002, 14: 158-160

112 Hsu CL, Li HH, Hsueh TJ. Water-and humidity-enhanced UV detector by using p-type La-doped $\mathrm{ZnO}$ NWs on flexible polyimide substrate. ACS Appl Mater Interfaces, 2013, 5: 11142-11151.

113 Lai CL, Wang XX, Zhao Y, Fong H, Zhu ZT. Effects of humidity on the ultraviolet nanosensors of aligned electrospun $\mathrm{ZnO}$ nanofibers. RSC Adv, 2013, 3: 6640-6645

114 Li YB, Valle FD, Simonnet M, Yamada I, Delaunay JJ. Competitive surface effects of oxygen and water on UV photoresponse of $\mathrm{ZnO}$ NWs. Appl Phys Lett, 2009, 94: 023110

Acknowledgements This work was supported by the National Natural Science Foundation of China (21322106, 21501060 and 51472097), National Basic Research Program of China (2015CB932600), Program for HUST Interdisciplinary Innovation Team (2015ZDTD038) and the Fundamental Research Funds for the Central University. The authors are indebted for the kind permission from the corresponding publishers/authors to reproduce their materials, especially figures used in this article.

Author contributions Zheng Z, Gan L and Zhai TY conceived the study. Zheng $Z$ and Gan L wrote the manuscript. Gan L and Zhai TY modified the manuscript. All authors discussed on the manuscripts structure, arguments and conclusions.

Conflict of interest The authors declare that they have no conflict of interest. 


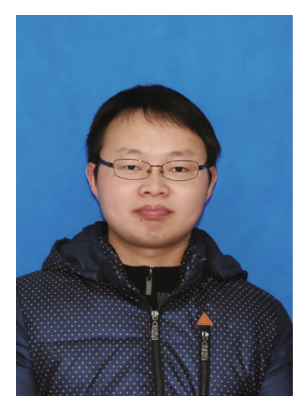

Zhi Zheng received his BSc degree in inorganic non-metallic materials from Shaanxi University of Science and Technology in 2012. Currently, he is a PhD candidate in Prof. Tianyou Zhai's group at the School of Materials Science and Engineering, HUST. His scientific research concentrates on the preparation of NWs via electrospinning for electronic and optoelectronic devices.

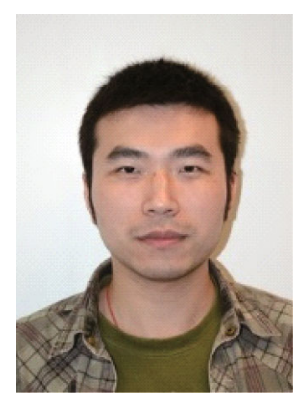

Lin Gan received his BSc degree in chemistry from Wuhan University in 2005, and $\mathrm{PhD}$ degree in physical chemistry from Peking University under the supervision of Prof. Xuefeng Guo in 2012. Currently, he is working at the School of Materials Science and Engineering, HUST. His research interest focuses mainly on the chemical vapor deposition (CVD) synthesis of two-dimensional (2D) nanomaterials, such as graphene, TMDs, etc., and the electronic/optoelectronic properties and applications of these $2 \mathrm{D}$ materials.

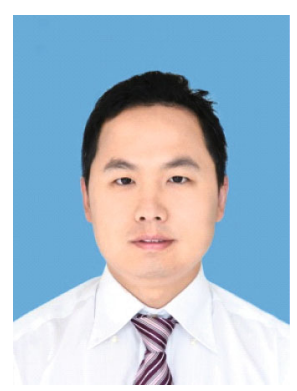

Tianyou Zhai received his BSc degree in chemistry from Zhengzhou University in 2003, and then received his PhD degree in physical chemistry from the Institute of Chemistry, Chinese Academy of Sciences (ICCAS) under the supervision of Prof. Jiannian Yao in 2008. Afterwards he joined the National Institute for Materials Science (NIMS) as a JSPS postdoctoral fellow of Prof. Yoshio Bando's group and then as an ICYS-MANA researcher within NIMS. Currently, he is a Chief Professor of the School of Materials Science and Engineering, HUST. His research interests include the controlled synthesis and exploration of fundamental physical properties of inorganic functional nanomaterials, as well as their promising applications in energy science, electronics and optoelectronics.

\footnotetext{
静电纺丝法制备纳米线阵列及其在电子与光电子领域中的应用

郑志, 甘霖, 翟天佑

摘要 一维纳米线的有序化排列问题, 是决定其未来在高集成微纳电路中应用前景的关键因素. 本综述对目前能够实现纳米线有序化排列的技 术方法做了一个简要的归纳, 重点阐述静电纺丝技术在纳米线制备和有序化排列方面的优势及相关技术和应用进展. 本文首先按技术特点将目 前纳米线有序化排列技术大致分为“先生长后排列”, “先排列后生长”以及“边生长边排列(即静电纺丝技术)”三大类, 并对各类方法的优缺点进行 了简要评述. 然后着重介绍静电纺丝技术及其相关技术进展, 并进一步展示了当前基于静电纺丝技术制备的纳米线阵列在微纳电极、场效应晶 体管、传感器以及光探测器等方向的应用. 最后就静电纺丝技术的未来发展做了简要展望. 综上, 由于静电纺丝技术在一维材料制备及其有序化 排列方面的简便性和低成本优势, 其必将在基于一维材料的电子学/光电子学领域具有广阔的应用前景.
} 